\title{
Managing treatment-experienced pediatric and adolescent HIV patients: role of darunavir
}

This article was published in the following Dove Press journal:

Therapeutics and Clinical Risk Management

30 July 2009

Number of times this article has been viewed

\author{
Michael Neely \\ Andrea Kovacs \\ University of Southern California \\ Keck School of Medicine, Department \\ of Pediatrics, Division of Infectious \\ Diseases, Los Angeles, CA, USA
}

\begin{abstract}
Darunavir is currently the most recently approved HIV-1 protease inhibitor. It is approved for twice-daily dosing with ritonavir in treatment-experienced patients as young as 6 years of age and is available in numerous pill strengths. Emergence of darunavir-specific mutations is generally slow; therefore it can retain activity against viral strains that are resistant to other protease inhibitors, including tipranavir. Darunavir pharmacokinetics, clinical efficacy, resistance mutations and pharmacodynamics, and adverse effects are reviewed here. Substantial data support its use as a potent, well-tolerated option for salvage therapy in highly treatmentexperienced children and adolescents.
\end{abstract}

Keywords: darunavir, protease inhibitors, treatment, child, adolescent

\section{Introduction}

As of 2007, 2 million children under 15 years of age were living with HIV in the world, with approximately 370,000 new infections and 270,000 deaths that year. ${ }^{1}$ Of the 2.3 million new adult infections in $2007,45 \%$ (over 1 million) were in adolescents aged 15 to 24 years of age. In some developing countries, seroprevalence of HIV among adolescent males is higher than 5\%, with females 2 to 4 times higher still, reflecting the burden of the epidemic borne by girls and women.

Nonetheless, in countries that have the resources and infrastructure to ensure consistent access to combination antiretroviral therapy, the trajectory of the epidemic has been dramatically altered. For example, in North America, the seroprevalence rate among adults was only $0.6 \%$ in 2007 , and there were estimated to be just 4400 children living with HIV infection, with fewer than 500 new infections that year in those under 15 years of age. ${ }^{1}$ Despite the low burden of HIV infection in developed countries relative to the developing world, the most treatment-experienced children and adolescents presently reside and obtain care in regions of the world such as the United States (US) and Europe. As therapy is increasingly available worldwide, however, the number of treatment-experienced children will correspondingly rise globally. For these young patients, there is and will be a chronic and pressing need for drugs that are active against HIV strains which are resistant to multiple antiretroviral agents. ${ }^{2}$

Control of HIV infection is accomplished through the use of combination antiretroviral therapy. ${ }^{3}$ There are now six therapeutic classes of medications available, as shown in Table 1, although not all are licensed for use in children. Entry inhibitors include CCR5 antagonists and fusion inhibitors. The former bind to the human
1640 Marengo St., Suite 300, Los Angeles, CA 90033 , USA

$\mathrm{Tel}+\mathrm{I}(323) 226-2330$

Fax + I (323) 226-2505

Email mneely@usc.edu 
Table I Current lower age of FDA-licensure for antiretroviral drugs obtained from package inserts

\begin{tabular}{ll}
\hline Drug & $\begin{array}{l}\text { Lower age for licensed } \\
\text { prescribing }\end{array}$ \\
\hline
\end{tabular}

Nucleoside reverse transcriptase

inhibitors

Abacavir $\left(\right.$ Ziagen $\left.{ }^{\circledR}\right)$
Didanosine $\left(\right.$ Videx $^{\circledR}$, Videx $\left.\mathrm{EC}^{\circledR}\right)$
Emtricitabine $\left(\right.$ Emtriva $\left.^{\text {Tw}}\right)$
Lamivudine $\left(\right.$ Epivir $\left.^{\circledR}\right)$
Stavudine $\left(\right.$ Zerit $\left.^{\circledR}\right)$
Tenofovir disoproxil fumarate
$\left(\right.$ Viread $\left.^{\circledR}\right)$

Zidovudine (Retrovir ${ }^{\circledR}$ )

Nonnucleoside reverse transcriptase inhibitors

\begin{tabular}{|c|c|}
\hline Efavirenz (Sustiva $^{T M}$ ) & 3 years \\
\hline Etravirine (Intelence ${ }^{T M}$ ) & 16 years \\
\hline Nevirapine (Viramune $\left.{ }^{\circledR}\right)$ & 15 days \\
\hline \multicolumn{2}{|l|}{ Combination NRTI and/or NNRTI } \\
\hline Abacavir + lamivudine (Epzicom $\left.{ }^{\circledR}\right)$ & 16 years \\
\hline $\begin{array}{l}\text { Abacavir }+ \text { lamivudine }+ \text { zidovudine } \\
\left(\text { Trizivir }^{\circledR}\right)\end{array}$ & Variable $(>40 \mathrm{~kg})$ \\
\hline Tenfovir + emtricitabine $\left(\right.$ Truvada $\left.^{\circledR}\right)$ & 18 years \\
\hline $\begin{array}{l}\text { Tenfovir + emtricitabine + Efavirenz } \\
\left(\text { Atripla }^{\circledR}\right)\end{array}$ & 18 years \\
\hline Zidovudine + lamivudine $\left(\right.$ Combivir $\left.^{\circledR}\right)$ & 12 years \\
\hline \multicolumn{2}{|l|}{ rotease inhibitors (PI) } \\
\hline Atazanavir (Reyataz ${ }^{T M}$ ) & 6 years \\
\hline Darunavir (Prezista ${ }^{\circledR}$ ) & 6 years \\
\hline Fos-amprenavir (Lexiva ${ }^{\mathrm{TM}}$ ) & 2 years \\
\hline Indinavir (Crixivan $\left.{ }^{\circledR}\right)$ & 18 years \\
\hline Lopinavir/ritonavir (Kaletra ${ }^{\circledR}$ ) & 14 days \\
\hline Nelfinavir $\left(\right.$ Viracept $\left.^{\circledast}\right)$ & 2 years \\
\hline Ritonavir (Norvir ${ }^{\circledR}$ ) & $\begin{array}{l}2 \text { years (treatment); variable as } \\
\text { boosting agent with other Pls }\end{array}$ \\
\hline Saquinavir (Invirase ${ }^{\circledR}$ ) & 16 years \\
\hline Tipranavir (Aptivus ${ }^{\circledR}$ ) & 2 years \\
\hline \multicolumn{2}{|l|}{ ntry and fusion inhibitors } \\
\hline Enfuvirtide $\left(\right.$ Fuzeon $\left.^{\mathrm{TM}}\right)$ & 6 years \\
\hline Maraviroc (Selzentry $\left.{ }^{\circledR}\right)$ & 16 years \\
\hline \multicolumn{2}{|l|}{ ntegrase inhibitor } \\
\hline Raltegravir $\left(\right.$ Isentress $\left.^{\circledast}\right)$ & 16 years \\
\hline
\end{tabular}

membrane receptor CCR5 to prevent binding of virions to susceptible cells. They are the only therapeutic agents with a human target. Fusion inhibitors disrupt the process by which virions inject their contents into the target cell cytoplasm by binding to the viral gp41 protein, which is essential to the process. Nucleoside reverse transcriptase inhibitors (NRTIs) are analogues of nucleosides/tides (eg, adenine, guanine, cytosine, thiamine) and are competitive antagonists of the reverse transcription step from viral RNA to doublestranded DNA. Non-NRTIs (NNRTIs) similarly inhibit this step, but through a noncompetitive antagonism. Integrase inhibitors prevent the insertion of proviral DNA into the host cell genome. Finally, protease inhibitors (PIs) stop cleavage and activation of the viral gag-pol polyprotein by the viral protease.

The first PI licensed for adults by the US Food and Drug Administration (FDA) in December 1995 was saquinavir $\left(\right.$ Invirase ${ }^{\circledR}$ ), ushering in the era of effective combination therapy for HIV. Saquinavir was followed shortly thereafter by ritonavir $\left(\right.$ Norivr $\left.^{\circledR}\right)$ and indinavir $\left(\right.$ Crixivan $\left.^{\circledR}\right)$ in March 1996. There have since been 8 additional PIs brought to market, many with overlapping resistance profiles. In this article we review darunavir (Prezista ${ }^{\mathrm{TM}}$, Tibotec Pharmaceuticals), currently the most recently licensed PI. We will consider the activity of darunavir against HIV strains resistant to many or all other PIs and its role in the management of HIV-infected children and adolescents.

\section{Darunavir description and approval history}

Darunavir is a nonpeptidic inhibitor of HIV-1 and HIV-2 protease, and like other PIs, it prevents cleavage of the HIV polyprotein encoded by the gag-pol region. Darunavir, and its structural analogue, amprenavir, both bind to a unique site on the wild-type protease enzyme at a rate approximately one order of magnitude faster than other protease inhibitors, including tipranavir. ${ }^{4}$ Furthermore, darunavir disassociates from the wild type protease at a rate $>1000$-fold more slowly than that of other protease inhibitors, including amprenavir and tipranavir. Together, darunavir's rapid binding and slow disassociation confer a binding strength two orders of magnitude higher than any other protease inhibitor, which is believed to confer potency even against viral strains resistant to other PIs. ${ }^{4-6}$

Darunavir is one of 28 unique or combined-formulation antiretroviral drugs currently licensed by the FDA and available for use by HIV-infected adults. Of these medications, $19(68 \%)$ are also licensed for use in HIV-infected children and adolescents, defined by the US Code of Federal Regulations ${ }^{7}$ as less than 16 years of age, although the lower age limit for licensed dosing varies by drug, as shown in Table 1 . Among the agents from new therapeutic classes (maraviroc and raltegravir) or the "second-generation" agents in older 
classes (darunavir, tipranavir, and etravirine), only darunavir and tipranavir are FDA-licensed for children and adolescents. Darunavir was originally licensed on June 23, 2006, and the label was modified to include children on December 18 , 2008. In the US it is approved for the treatment of HIV-1 infection in treatment-naïve and treatment-experienced adults and treatment-experienced children over 6 years of age. It is not currently licensed for children in Europe, although application has been submitted for licensure as young as 3 years of age.

\section{Pharmacokinetics}

Although the majority of pharmacokinetic information for darunavir has been obtained from adults, DELPHI (Darunavir EvaLuation in Pediatric HIV-1-Infected treatmentexperienced patients, TMC 114-C212) was an open-label, Phase I/II manufacturer-sponsored investigation to determine the pharmacokinetics, safety, and efficacy of darunavir in children and adolescents. ${ }^{8-10}$ After 2 weeks of dosing, darunavir plasma concentrations were measured to obtain pharmacokinetic, safety and efficacy data from 44 children. Pharmacokinetic results from DELPHI and from adult studies are summarized in Table 2. With the goal of best matching adult darunavir exposures measured after dosing with darunavir $600 \mathrm{mg}$ plus ritonavir $100 \mathrm{mg}$ twice daily, the final pediatric dosing recommendations, shown in Table 3, were selected for the 48-week safety and efficacy Part II of the DELPHI study (discussed in the Clinical Experience section). These are the same weight-based recommendations as those included in the FDA-approved package insert.

Food, while slowing the rate of darunavir absorption ${ }^{11}$ also increases the overall bioavailability by $30 \%$ relative to the fasted state, and thus the drug should be given with food; however, meal composition is irrelevant. ${ }^{11,12}$ Metabolism is almost exclusively by cytochrome P450 (CYP) 3A4; ${ }^{12}$ therefore, darunavir is to be administered with low-dose ritonavir, which is a potent CYP3A4 inhibitor ${ }^{12}$ and raises the concentrations of darunavir significantly. Approximately $80 \%$ of darunavir is eliminated in the feces, half of which is unchanged parent compound when given with ritonavir. ${ }^{13}$

On October 21, 2008, the FDA licensed an amended once-daily dosing regimen for darunavir in treatment-naïve HIV-infected adults. In this population the approved daily dose is $800 \mathrm{mg}$ in combination with ritonavir $100 \mathrm{mg}$. Darunavir at this dose was studied as one of several darunavir dosing arms vs comparator protease inhibitors in the POWER-1 and -2 (Performance Of TMC114/r When evaluated in treatment-Experienced patients with PI Resistance) studies $^{14}$ and as the only darunavir treatment arm vs once or twice daily lopinavir/ritonavir in the ARTEMIS trial

Table 2 Pharmacokinetics of darunavir in children and adults from the US Package Insert ${ }^{12}$ and other references as noted

\begin{tabular}{|c|c|c|}
\hline \multicolumn{3}{|l|}{ Observation or parameter (adult patients) } \\
\hline Protein binding & \multicolumn{2}{|l|}{$95 \%$} \\
\hline \multicolumn{3}{|l|}{ Bioavailability, absolute } \\
\hline without ritonavir & \multicolumn{2}{|l|}{$37 \%$} \\
\hline with ritonavir & \multicolumn{2}{|l|}{$82 \%$} \\
\hline \multicolumn{3}{|l|}{ Bioavailability, relative } \\
\hline food"l & \multicolumn{2}{|l|}{$+30 \%$} \\
\hline $\mathrm{T}_{\max }{ }^{\mathrm{a}}$, hours & \multicolumn{2}{|l|}{$2.5-4.0$} \\
\hline Terminal half-life, hours & \multicolumn{2}{|c|}{15 (when co-administered with ritonavir) } \\
\hline Clearance, $\mathrm{L} / \mathrm{h}$ (intravenous dosing with ritonavir) & \multicolumn{2}{|l|}{5.9} \\
\hline Volume of distribution, L (intravenous dosing) $)^{51}$ & \multicolumn{2}{|l|}{$|3|$} \\
\hline Effect of hepatic impairment & \multicolumn{2}{|c|}{ No significant change with moderate impairment (Child-Pugh Class B) } \\
\hline Effect of renal impairment & \multicolumn{2}{|c|}{ No significant change with moderate impairment (creatinine clearance $30-60 \mathrm{~mL} / \mathrm{min}$ ) } \\
\hline Typical darunavir & Pooled POWER I and 2 & DELPHI \\
\hline concentrations $^{\mathrm{b}}$ & $\mathrm{N}=119$ adults & $\mathrm{N}=74$ children \\
\hline $\mathrm{AUC}_{0-24}, \mu \mathrm{g} \cdot \mathrm{h} / \mathrm{mL}^{\mathrm{c}}$ median (range) & $123.3(67.7-2 \mid 3.0)$ & I $27.3(67 . \mid-230.7)$ \\
\hline $\mathrm{C}_{0 h}, \mu g / \mathrm{mL}^{\mathrm{d}}$ median (range) & $3.5(1.3-7.4)$ & $3.9(1.8-7.8)$ \\
\hline
\end{tabular}

${ }^{a}$ Time to maximum concentration

'Observed after darunavir $600 \mathrm{mg}$ plus ritonavir $100 \mathrm{mg}$ twice daily in adults, and according to dosing in Table 2 in children.

'Area under the time-concentration curve from 0 to 24 hours, calculated as $2 * A \cup C_{0-12}$.

${ }^{\mathrm{d}}$ Concentration immediately prior to dosing, ie. trough concentration. 
Table 3 FDA-licensed darunavir/ritonavir dosing in children and adolescents

\begin{tabular}{lllll}
\hline Weight & & & Dose \\
\cline { 1 - 2 } $\mathbf{( k g )}$ & (lbs) & & (darunavir $\mathbf{~ m g )}$ & (ritonavir $\mathbf{~ m g )}$ \\
\hline 20 to $<30$ & 44 to $<66$ & 375 & 50 \\
30 to $<40$ & 66 to $<88$ & 450 & 60 \\
$\geq 40$ & $\geq 88$ & 600 & 100 \\
\hline
\end{tabular}

(AntiRetroviral Therapy with TMC114 ExaMined In naïve Subjects). ${ }^{15}$ With once-daily dosing in adults, the AUC of $87.9 \mathrm{mg} \cdot \mathrm{h} / \mathrm{L}$ and $\mathrm{C}_{0}$ of $2.0 \mathrm{mg} / \mathrm{L}^{12}$ are $71 \%$ and $57 \%$ of the twice-daily adult dose. ${ }^{12}$ However, there is no experience with once-daily dosing of darunavir in children or adolescents, and it is not recommended. ${ }^{12}$

In the US, darunavir is supplied as film-coated tablets in strengths of $75,300,400$, and $600 \mathrm{mg}$, which are stable at room temperature. There is a nonlicensed liquid formulation which has been used in clinical research only.

In summary, darunavir is available in numerous dosage strengths which make weight-based dosing in children feasible, although a liquid formulation is not currently on the market. The drug is approved for use in children as young as six years of age and the dosing recommendations in Table 3 approximate the exposures seen in adults who are given $600 \mathrm{mg}$ in combination with ritonavir $100 \mathrm{mg}$, both twice daily. Once daily dosing has not been studied in children and is not currently recommended.

\section{Drug interactions}

Darunavir itself is both a substrate and inhibitor of CYP3A $4,{ }^{12}$ and is always co-administered with ritonavir. Ritonavir interacts with several drug metabolizing enzymes in complex and opposing ways. It is a potent inhibitor of CYP3A4, and a lesser inhibitor of CYP2D6. ${ }^{12}$ On the other hand, it is an inducer of several cytochromes P450, including 1A2, 2B6, $2 \mathrm{C} 9$, and $2 \mathrm{C} 19$, as well as glucuronyl transferase. ${ }^{16}$ Therefore, there is significant potential for drug-drug interactions. In general, concomitant medications which are primarily metabolized by CYP3A4 or 2D6 will tend to have increased concentrations, due to inhibition of these enzymes by the combination of darunavir and ritonavir, while medications metabolized by other CYP isoforms will have lowered concentrations due to induction of metabolism by ritonavir. ${ }^{12}$ Darunavir has been studied in combination with other antiretroviral agents and many nonantiretroviral drugs, all of which are reported in the package insert ${ }^{12}$ and summarized in Table 4. A useful, continuously updated resource for interactions involving antiretroviral agents is the HIV Drug Interaction website (http://www.hiv-druginteractions.org), maintained by the University of Liverpool.

The most significant interactions with other antiretrovirals to avoid are lopinavir and saquinavir which lower darunavir concentrations. Both darunavir and indinavir concentrations are somewhat raised with coadministration, so this combination should only be used with caution. Atazanavir, efavirenz, etravirine, nevirapine, and tenofovir disoproxil fumarate have all been shown to lack a significant interaction with darunavir.

\section{Clinical efficacy}

Major clinical trials to establish the efficacy and safety of darunavir in patients are summarized in Table 5. Efficacy will be discussed here, while safety and tolerability will be discussed separately. Published clinical experience with darunavir in children and adolescents is limited to a case report of successful darunavir-based salvage therapy in a single child with multi-drug resistant, perinatally transmitted $\mathrm{HIV}^{17}$ and abstracts/posters from the DELPHI study of 80 PI-experienced children ages 6-17 years with baseline viral loads $>1000$ copies $/ \mathrm{mL}$, who received 48 weeks of darunavir plus ritonavir plus optimized background therapy. ${ }^{8,10}$ Baseline characteristics of the DELPHI study population are shown in Table 6. At 48 weeks, the percent of children with $\geq 1 \log _{10}$ drop in viral load from baseline was $65 \%$ and the percent with $<50$ copies $/ \mathrm{mL}$ was $48 \%$. In accordance with FDA guidelines, analysis was by intent to treat, time to loss of virologic control (ITT-TLOVR), where success for a given virologic endpoint is defined only in those who did not withdraw, whose regimen was not switched for virologic failure, and who had reached the endpoint on two consecutive visits, with no subsequent failure before end of study. ${ }^{18}$ All others are considered failures. The mean change in $\mathrm{CD} 4+$ cell count was +147 cells $/ \mathrm{mm},{ }^{3}$ with analysis by ITT-noncompleter equals failure (ITT-NC $=\mathrm{F}$ ), where missing data from individuals due to premature study termination or missed visits are replaced with baseline values.

These response and adverse effect rates are comparable to those observed in adults in the POWER studies. ${ }^{19}$ POWER 1 and 2 were Phase IIB studies in different geographic regions, which compared the safety and efficacy of darunavir/ritonavir (600/100 mg twice daily) or placebo plus an optimized background antiretroviral regimen in highly treatment-experienced adults, similar to the children and adolescents in DELPHI. POWER 3 was an extension of POWER 1 and 2 in order to satisfy regulatory requirements; 


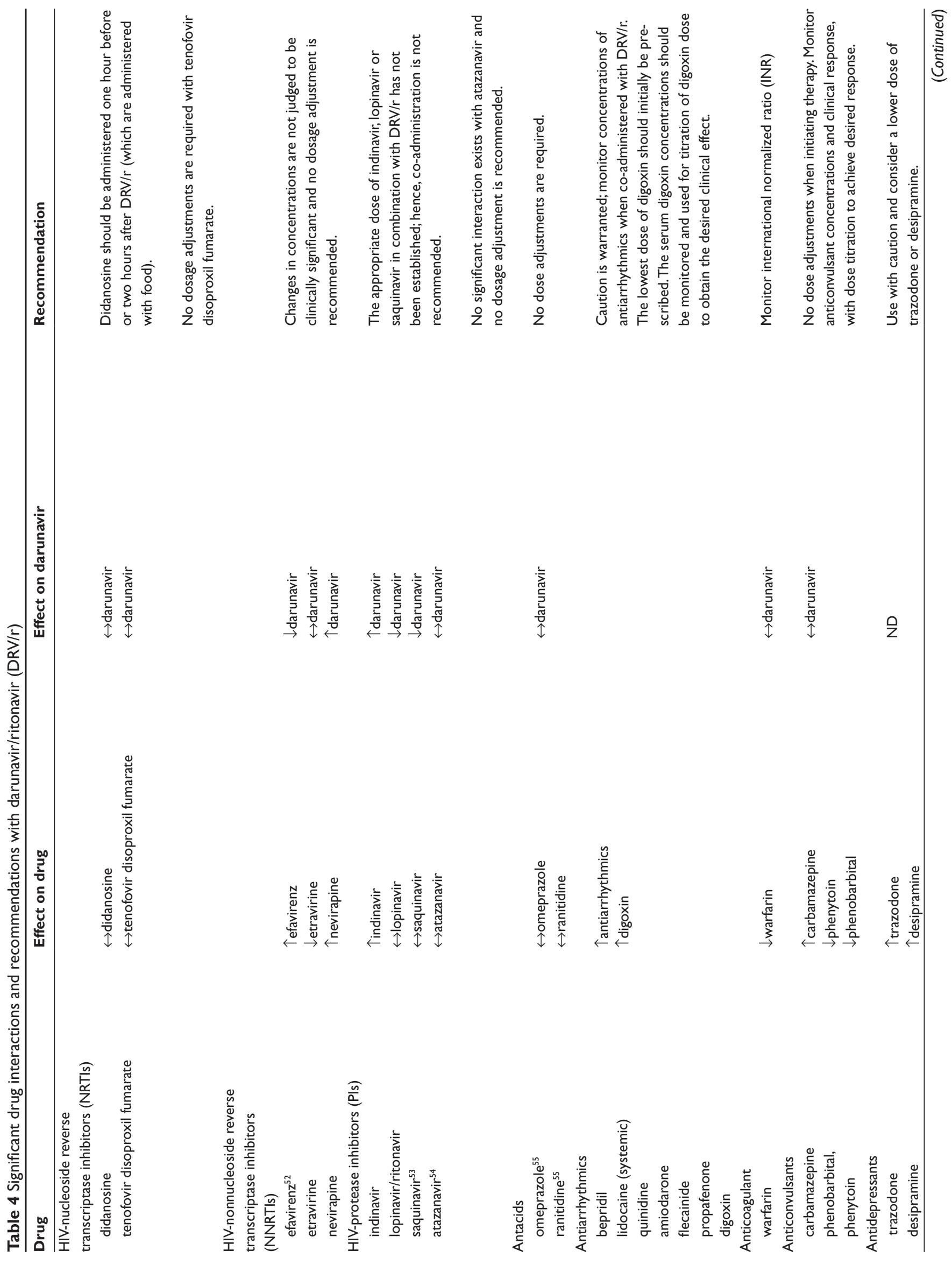




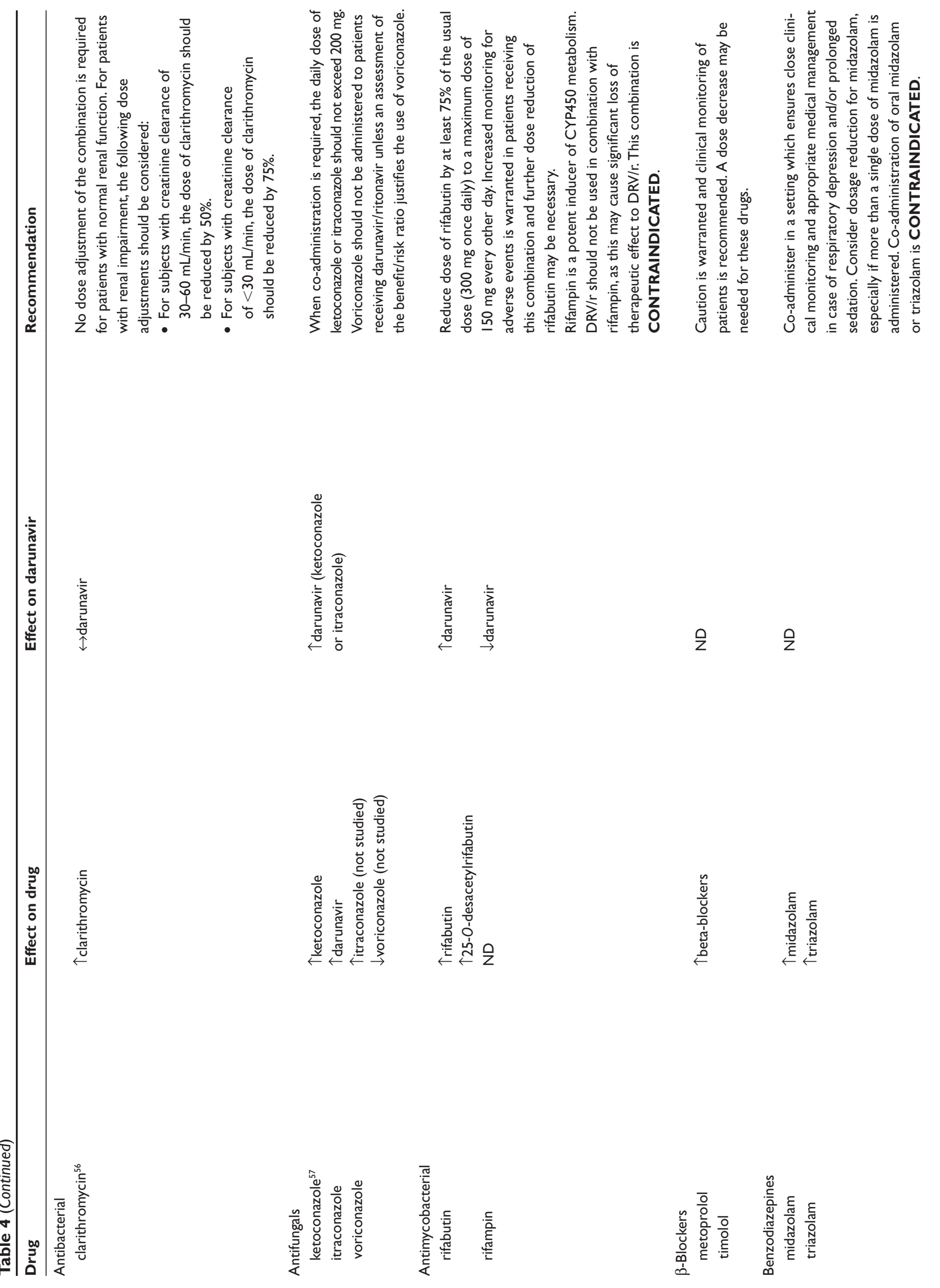



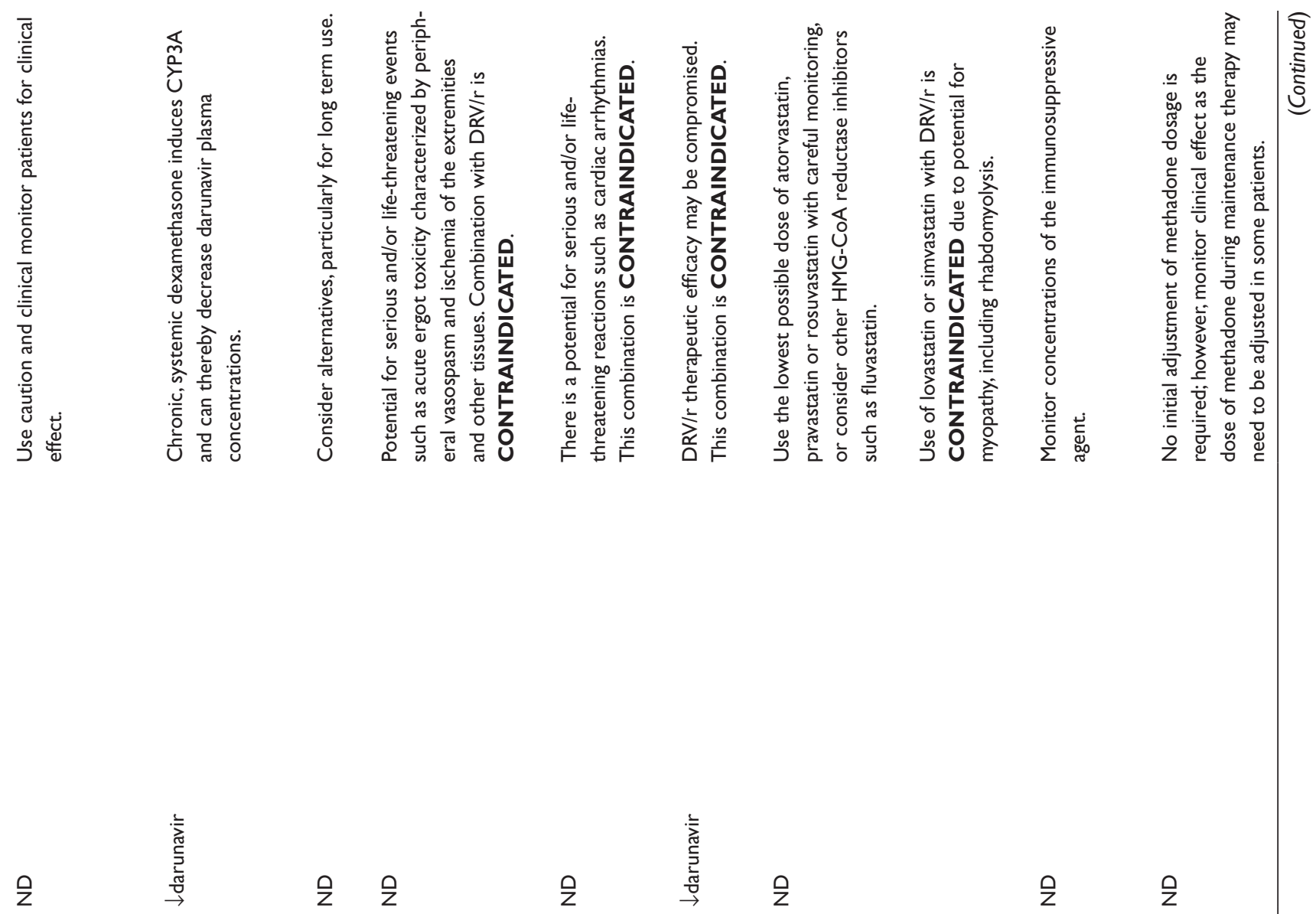

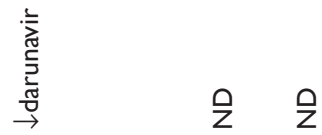

१

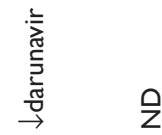

号

१

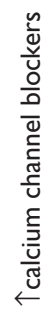

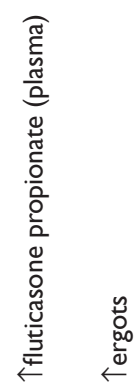

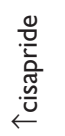

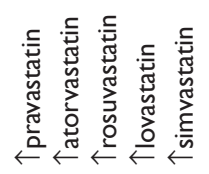

々
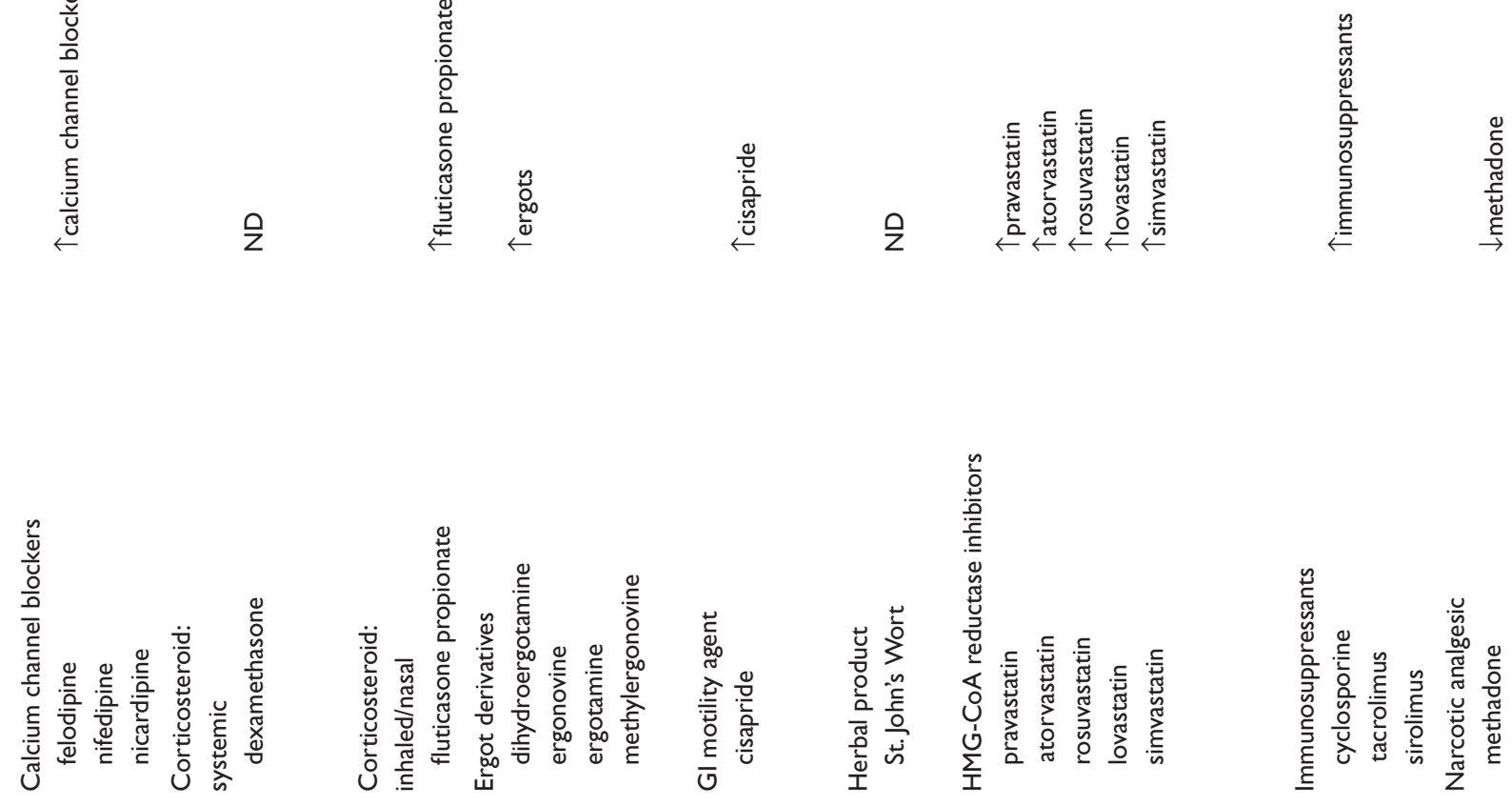


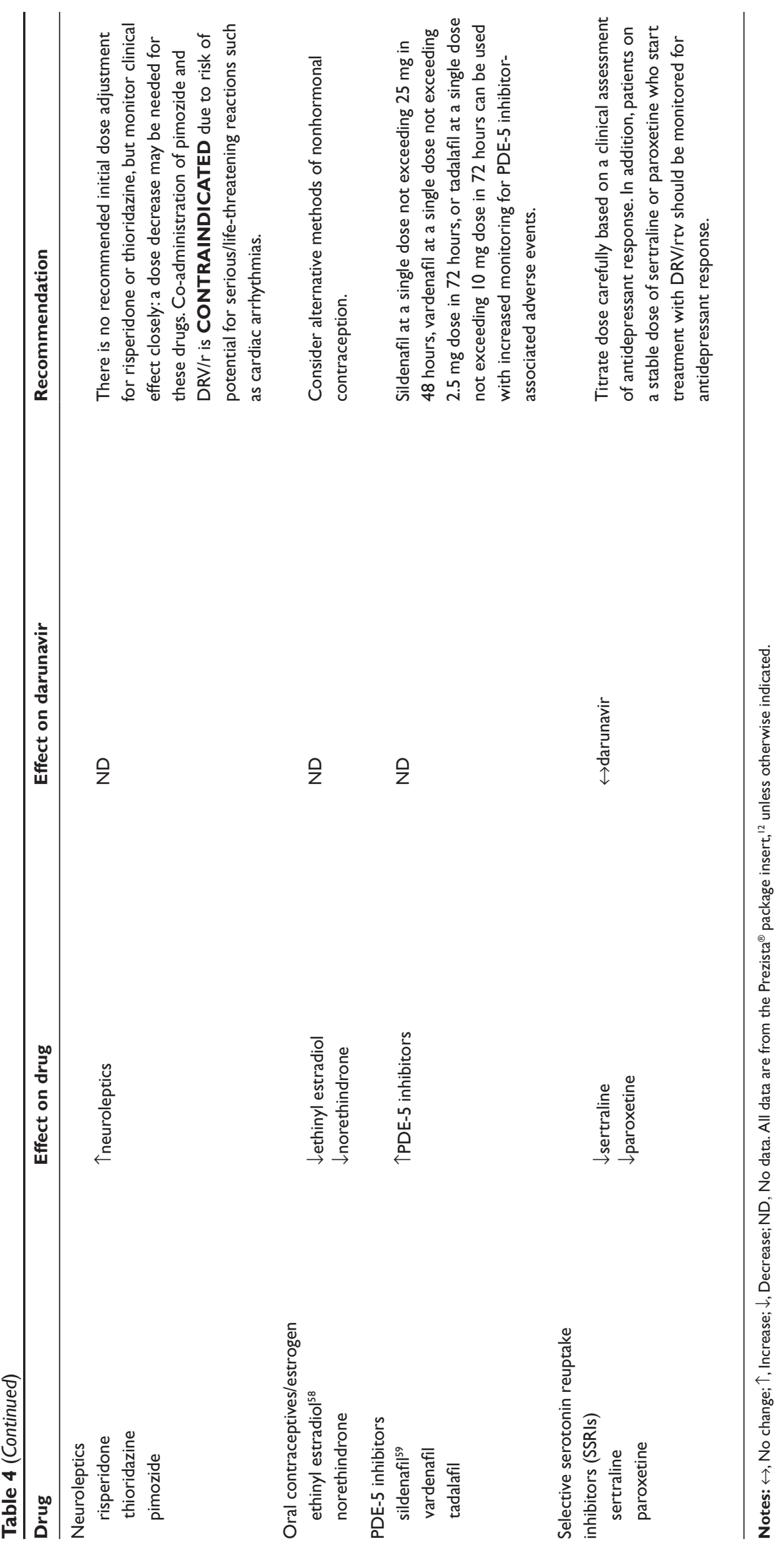


however, a placebo arm was not included in POWER 3. ${ }^{20}$ At week 48, combined analysis of 230 participants from POWER 1 and 2 showed a drop of $\geq 1 \log _{10}$ viral copies $/ \mathrm{mL}$ from baseline in $61 \%$ of the participants, and $45 \%$ of them achieved $<50$ copies $/ \mathrm{mL}^{19}$ (compared with $65 \%$ and $48 \%$ of the DELPHI participants). In addition to baseline PI mutations and RAMs, the number of active NRTIs in the background regimen was strongly associated with $\geq 1 \log _{10}$ drop in viral copies/mL: $42 \%$ in the darunavir arm vs none in the comparator arm reached this endpoint with no active NRTIs $(\mathrm{P}<0.0001)$; with one active NRTI it was $69 \%$ and $13 \%$ $(P<0.0001)$; and with $\geq 2$ active NRTIs, it was $68 \%$ and $28 \%(P=0.001)$. The mean CD4+ cell increase in POWER 1 and 2 was 102 cells $/ \mathrm{mm}^{3}$ (compared with 147 in the children and adolescents in the DELPHI cohort). Virologic and immunologic results were very similar from the additional patients in POWER 3, as shown in Table 5. ${ }^{20}$

Not surprisingly, given the structural similarity to amprenavir, a previous history of failure with fos-amprenavir was associated with reduced response to darunavir. ${ }^{21}$ In the POWER and DUET studies, average 48-week viral load change from baseline was $-1.47 \log _{10}( \pm 0.15)$ copies $/ \mathrm{mL}$ in 73 patients with a history of failure on an amprenavir-based regimen vs $-1.65 \log _{10}( \pm 0.06)$ copies $/ \mathrm{mL}$ in 450 patients regardless of prior amprenavir exposure $(P<0.0001$, T-Test). ${ }^{22}$ Although this was highly statistically significant, it has been argued that the clinical significance of a $0.3 \log _{10}$ difference is minimal ${ }^{23}$ and the percentage of those achieving $<50$ copies $/ \mathrm{mL}$ in each group at 48 weeks was not significantly different ( $38 \%$ vs $45 \%, P=0.40$, Chi-square).

ARTEMIS was a Phase III, randomized, open-label, noninferiority comparison of either darunavir/ritonavir (800/100 mg once daily) or lopinavir/ritonavir plus optimized background antiretrovirals in treatment-naïve adults. ${ }^{15}$ Therefore, the ARTEMIS study population was different than the DELPHI and POWER populations by prior treatment experience. Accordingly, virologic response rates were higher in ARTEMIS, with $84 \%$ of 343 participants in the darunavir arm achieving $<50$ copies $/ \mathrm{mL}$ at week 48 , which was not inferior to the lopinavir arm (78\% of 346). The median changes in CD4+ cell count at week 48 were +137 and +141 cells $/ \mathrm{mm}^{3}$ for darunavir and lopinavir, respectively.

TITAN (TMC114/r In Treatment-experienced pAtients Naïve to lopinavir) was a Phase III, randomized, open label companion trial to ARTEMIS, which again compared darunavir to lopinavir, but in a treatment-experienced population who were naïve to lopinavir, although participants did not have to be susceptible to lopinavir at baseline. ${ }^{24}$
Participants were randomized 1:1 to either darunavir/ritonavir 600/100 mg twice daily, or lopinavir/ritonavir 400/100 mg twice daily. Both study arms included optimized background therapy, but enfuvirtide was excluded. At 48 weeks, $71 \%$ of the patients in the darunavir arm had $<50$ viral copies $/ \mathrm{mL}$ by ITT-TLOVR analysis, vs $60 \%$ in the lopinavir arm $(P=0.005)$. Similarly, the mean change in viral load from baseline was $-1.95 \mathrm{vs}-1.72 \log _{10}$ copies $/ \mathrm{mL}$ in the darunavir and lopinavir arms, respectively $(P=0.046)$. Among patients with baseline reduced susceptibility to lopinavir, the percentage in each group with $<50$ viral copies $/ \mathrm{mL}$ was $72 \%$ vs $28 \%$, highlighting the usefulness of darunavir in the setting of baseline lopinavir resistance. The mean change in CD4+ cells was not significantly different in the two arms: +88 vs +81 cells $/ \mu \mathrm{L}$.

In summary, darunavir has demonstrated virologic and immunologic efficacy in highly treatment-experienced children and adolescents which closely matches the efficacy in treatment-experienced adults. Darunavir has not been studied in treatment-naïve children and adolescents, but is effective in treatment-naïve adults. Prior failure with amprenavir or fos-amprenavir may be associated with slightly reduced efficacy, due to structural similarities between amprenavir and darunavir.

\section{Pharmacokinetic- pharmacodynamic predictors of darunavir clinical efficacy}

Numerous pharmacokinetic and pharmacodynamic factors have been studied to predict virologic and immunologic responses to darunavir therapy, including baseline darunavir susceptibility, darunavir drug concentrations, total number of active drugs in the regimen, and inhibitory quotients. These are summarized in Table 7 and detailed in the following sections.

Susceptibility of HIV isolates to antiretroviral agents at baseline prior to starting new therapy or at the time of therapeutic failure may be broadly measured using one of two techniques: phenotypic or genotypic, with a third technique a hybrid of the two known as a virtual phenotype. ${ }^{25}$ Phenotypic susceptibility is reported as the concentration of drug required to inhibit laboratory growth of the patient's dominant viral strains by $50 \%\left(\mathrm{IC}_{50}\right)$, or as the fold-change in $\mathrm{IC}_{50}$ relative to the $\mathrm{IC}_{50}$ for wild-type virus. A related but not equal parameter is the concentration required for $50 \%$ of maximal in vivo or clinical effect $\left(\mathrm{EC}_{50}\right)$, which is a benchmark defined through clinical testing: against wild-type virus, the protein-corrected 


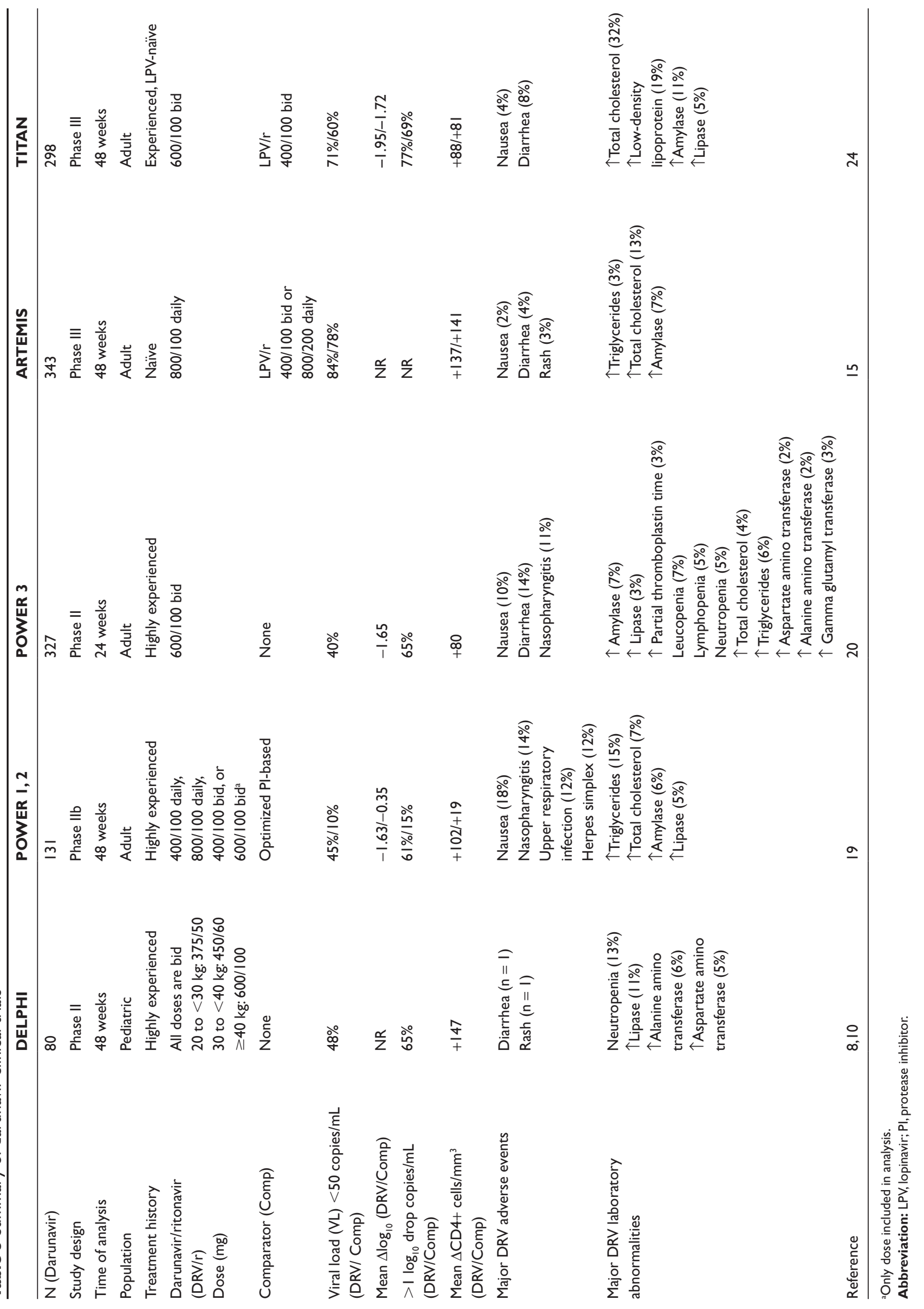


darunavir $\mathrm{EC}_{50}$ is $55 \mathrm{ng} / \mathrm{mL} .{ }^{15}$ Genotypic susceptibility is reported as a list of mutations in the patient's dominant viral strains, along with rules-based interpretations, ie,susceptible, possibly resistant, or resistant. The virtual phenotype provides an estimation of viral $\mathrm{IC}_{50}$ or fold-change in $\mathrm{IC}_{50}$, and is calculated using the patient's genotype, a large database of paired viral genotype-phenotype measurements, and weighted linear regression techniques. ${ }^{26}$

Common measures to quantify concentration-effect relationships include comparisons of total drug exposure (AUC), trough drug concentrations, or inhibitory quotients (IQ) in virologic responders vs nonresponders. The IQ is calculated as the ratio of drug concentration to viral susceptibility to that drug. ${ }^{27}$ Typically, the predose trough concentration is the reference drug concentration, while susceptibility may be quantified as the fold change in $\mathrm{IC}_{50}$ relative to wild-type

Table 6 Baseline characteristics of the DELPHI pediatric cohort

\begin{tabular}{|c|c|}
\hline Demographics & n (\%) \\
\hline Male & $57(7 \mathrm{I})$ \\
\hline \multicolumn{2}{|l|}{ Age } \\
\hline 6 to $<12$ years & $24(30)$ \\
\hline 12 to 17 years & $56(70)$ \\
\hline Perinatal infection & $62(78)$ \\
\hline CDC class $C$ & $40(50)$ \\
\hline \multicolumn{2}{|l|}{ Disease characteristics } \\
\hline Mean (SD) viral load ( $\log _{10}$ copies/mL) & $4.64(0.80)$ \\
\hline Median (range) CD4+ cell count (cells $/ \mathrm{mm}^{3}$ ) & $330(6-1505)$ \\
\hline Median (range) CD4+ cell \% & $17(1-47)$ \\
\hline \multicolumn{2}{|l|}{ Previous antiretroviral treatment } \\
\hline Median (range) number of drugs & $9(3-19)$ \\
\hline$\geq \mathrm{I} P \mathrm{Pl}, \mathrm{n}(\%)$ & $77(96)$ \\
\hline$\geq$ I NNRTI, n (\%) & $63(79)$ \\
\hline$\geq 2$ NRTIs, n (\%) & $80(100)$ \\
\hline Enfuvirtide, $\mathrm{n}(\%)$ & $8(10)$ \\
\hline \multicolumn{2}{|l|}{ Baseline mutations } \\
\hline $\mathrm{Pl}$, median (range) number per patient & II (0-19) \\
\hline Major PI, median (range) number per patient & $3(0-6)$ \\
\hline \multicolumn{2}{|l|}{ Patients with darunavir RAMs, $\mathrm{n}$} \\
\hline 0 & 39 \\
\hline I & 17 \\
\hline 2 & 15 \\
\hline$\geq 3$ & 9 \\
\hline NNRTI, median (range) number per patient & $2(0-4)$ \\
\hline NRTI, median (range) number per patient & $4(0-8)$ \\
\hline
\end{tabular}

Abbreviations: CDC, Centers for Disease Control; NRTI, nucleoside reverse transcriptase inhibitors; NNRTI, non-nucleoside reverse transcriptase inhibitors; $\mathrm{PI}$, protease inhibitors; RAMs, resistance associated mutations. virus by phenotypic or virtual phenotypic assays (pIQ, vIQ) or by the number of resistance associated mutations (RAMs) by genotypic assay (gIQ).

\section{Genotypic susceptibility and outcomes}

Combined analysis ${ }^{28}$ from the POWER 1, 2 and 3 and DUET (etravirine plus placebo or darunavir in treatment-experienced patients) studies detected 11 darunavir Resistance Associated Mutations (RAMs) in 10 codons, which have been adopted in all three of the major HIV resistance databases (International AIDS Society-USA [IAS, http://www.iasusa. org], Stanford [http://hivdb.stanford.edu]., and French National Agency for AIDS Research [ANRS, http://www. hivfrenchresistance.org]). The mutations are V11I, V32I, L33F, I47V, I50V, I54L/M, T74P, L76V, I84V and L89V. Mutation overlap with other PIs according to IAS is shown in Table 8, although mutations for older drugs such as indinavir, nelfinavir and saquinavir are likely under-represented due to lack of current research. ${ }^{29}$

The Virco virtual phenotype database contains 82 unique mutations or pairs of mutations identified using their linear modeling algorithm which increase the fold-change in darunavir phenotypic $\mathrm{IC}_{50}$, including all of the 11 darunavirspecific RAMs. ${ }^{30}$ However, only four (I54L, T74P, L76V, and I84V) of these primary RAMs individually contribute more than a 2 -fold increase in darunavir $\mathrm{IC}_{50}$ (Virco, Inc., data on file). However, there is a relative paucity of primary darunavir RAMs in PI-resistant clinical samples submitted to Virco, ${ }^{28}$ suggesting that resistance to darunavir emerges slowly, and that darunavir can retain activity against viral quasispecies with a high degree of resistance to other PIs.

The number of darunavir RAMs present prior to therapy with darunavir is related to the degree of PI experience, and influences the success rate of darunavir therapy. In the combined POWER cohort, which was highly PI-experienced, there was a median of 12 PI RAMs prior to initiating therapy with darunavir. Among these PI RAMs, at least one was a darunavir RAM in $82 \%$ of patients , ranging up to 4 darunavir RAMs in $11 \%$ of the patients. ${ }^{31}$ The most commonly observed darunavir RAMs were L33F (42\%), I $84 \mathrm{~V}(39 \%)$, and I47V (13\%), with others ranging between $5 \%$ and $10 \%$. The probability of achieving a viral load of $<50$ copies $/ \mathrm{mL}$ ranged from $65 \%$ in those with no baseline darunavir RAMs, to only $10 \%$ in those with $\geq 4$ RAMs. In the PREDZISTA cohort, $89 \%$ of those with $<4$ darunavir RAMs achieved $<200$ copies $/ \mathrm{mL}$ at 12 weeks, vs none with $>5$ RAMs. ${ }^{32}$ 
Table 7 Significant pharmacokinetic and pharmacodynamic predictors of virologic response with darunavir-based therapy

\begin{tabular}{|c|c|c|}
\hline Predictor & Outcome & Notes \\
\hline \multicolumn{3}{|c|}{ Baseline virtual phenotypic susceptibility } \\
\hline & $\mathrm{VL}<50$ copies $/ \mathrm{mL}$ & POWER I, $2,3^{31}$ \\
\hline \multicolumn{3}{|l|}{ Susceptible (S) } \\
\hline$\left(\mathrm{IC}_{50} \mathrm{FC}<\mathrm{I0}\right)$ & $50 \%$ & \\
\hline \multicolumn{3}{|c|}{ Partial susceptibility $(\mathrm{P})$} \\
\hline$\left(\mathrm{IC}_{50} \mathrm{FC} \mathrm{I0-40)}\right.$ & $25 \%$ & \\
\hline \multicolumn{3}{|l|}{ Resistant (R) } \\
\hline \multirow[t]{2}{*}{$\left(\mathrm{IC}_{50} \mathrm{FC}>40\right)$} & $13 \%$ & \\
\hline & $\mathrm{VL}<200$ copies $/ \mathrm{mL}$ & PREDZISTA ${ }^{32}$ \\
\hline $\mathrm{S}: \mathrm{IC}_{50} \mathrm{FC}<10$ & $68 \%$ & \\
\hline $\mathrm{I}: \mathrm{IC}_{50} \mathrm{FC} 10-40$ & $46 \%$ & \\
\hline $\mathrm{R}: \mathrm{IC}_{50} \mathrm{FC}>40$ & $20 \%$ & \\
\hline \multicolumn{3}{|c|}{ Baseline darunavir RAMs } \\
\hline Number & $\mathrm{VL}<50$ copies $/ \mathrm{mL}$ & POWER I, 2, $3^{31}$ \\
\hline 0 & $65 \%$ & \\
\hline I & $50 \%$ & \\
\hline 2 & $40 \%$ & \\
\hline 3 & $20 \%$ & \\
\hline$\geq 4$ & $10 \%$ & \\
\hline Number & $\mathrm{VL}<200$ copies $/ \mathrm{mL}$ & PREDZISTA ${ }^{32}$ \\
\hline$<4$ & $89 \%$ & Identified darunavir RAMs differ from IAS, Stanford and \\
\hline $4-5$ & $52 \%$ & ANRS mutations \\
\hline$>5$ & $0 \%$ & \\
\hline \multicolumn{3}{|c|}{ Activity of background antiretroviral drugs } \\
\hline GSS & $\mathrm{VL}<50$ copies $/ \mathrm{mL}$ & POWER I, $2^{19}$ \\
\hline 0 & $20 \%$ & GSS calculated as the sum of each drug's score: \\
\hline I & $50 \%$ & 0 for resistant by genotype, I for susceptible \\
\hline$\geq$ & $56 \%$ & \\
\hline GSS & $\mathrm{VL}<200$ copies $/ \mathrm{mL}$ & PREDZISTA $^{32}$ \\
\hline 00.5 & $20 \%$ & GSS calculated as the sum of each drug's score: 0 for \\
\hline $\mathrm{I}-\mathrm{I} .5$ & $59 \%$ & resistant by genotype, 0.5 for possibly resistant, I for \\
\hline $2-3$ & $70 \%$ & susceptible \\
\hline \multicolumn{3}{|l|}{ Inhibitory quotients } \\
\hline vIQ & $\Delta V L>-I \log _{10}$ & POWER I, $2^{38}$ \\
\hline$\leq 0.1$ & $32 \%$ & \\
\hline 0.1 to $\leq 0.4$ & $61 \%$ & \\
\hline 0.4 to $\leq 1.4$ & $80 \%$ & \\
\hline$>1.4$ & $84 \%$ & \\
\hline vIQ & $\mathrm{VL}<50$ copies $/ \mathrm{mL}$ & Darunavir salvage therapy in $\mathrm{Pl}$-experienced adults ${ }^{39}$ \\
\hline$\leq 1.5$ & $29 \%$ & \\
\hline$>1.5$ & $71 \%$ & \\
\hline glQ & $\mathrm{VL}<200$ copies $/ \mathrm{mL}$ & PREDZISTA ${ }^{32}$ \\
\hline$\leq 1.8$ & $0 \%$ & \\
\hline$>1.8$ & $55 \%$ & \\
\hline
\end{tabular}

Notes and Abbreviations: $\mathrm{IC}_{50}, 50 \%$ inhibitory concentration in vitro; FC, fold change in $\mathrm{IC}_{50}$ relative to wild-type IC $;$; VL, viral load; $\mathrm{RAMs}$, resistance associated mutations; GSS, genotypic sensitivity score, which quantifies the activity of the additional antiretroviral drugs in the regimen based on genotype; vlQ, virtual phenotypic inhibitory quotient, which is the ratio of the trough darunavir concentration to the $I_{50}$ of the dominant strains as measured by virtual phenotype; glQ, genotypic inhibitory quotient which is the ratio of the trough darunavir concentration to the number of darunavir RAMs in the dominant viral strains.

In another, less PI-experienced cohort of 1021 patients who were failing PI therapy, and who had a median of 5 PI RAMS per patient, there was a lower prevalence of darunavir RAMs. I47V, I50V, 54L/M and L89V all had a frequency below $2.5 \%$; L33F and I84V had rates of $11 \%$ and $14.5 \%$, respectively. ${ }^{21}$ Only $6.7 \%$ of the patients had $\geq 3$ darunavir RAMs , and $68 \%$ had no darunavir RAMs. In those patients with $\geq 3$ darunavir RAMs the mean number of RAMs to all PIs was 12.3 compared with 5.3 in the patients with $<3$ darunavir RAMs $(P<0.0001)$. Together with the 
Table 8 Shared darunavir resistance mutations with other protease inhibitors ${ }^{29}$

\begin{tabular}{|c|c|c|c|c|c|c|c|c|c|c|}
\hline DRV & VIII & V32I & L33F & $147 V$ & I50V & I54LM & T74P & L76V & $184 \mathrm{~V}$ & L89V \\
\hline ATV $21 \%$ & & $\mathrm{~m}$ & $\mathrm{~m}$ & & $M$ & $\mathrm{~m}$ & & & $M$ & \\
\hline f-APV 55\% & & $\mathrm{m}$ & & $\mathrm{m}$ & $M$ & $\mathrm{~m}$ & & $\mathrm{~m}$ & $M$ & \\
\hline IDV 29\% & & $\mathrm{m}$ & & & & $\mathrm{m}$ & & $\mathrm{m}$ & $M$ & \\
\hline LPV $35 \%$ & & $M$ & $\mathrm{~m}$ & $M$ & $\mathrm{~m}$ & $\mathrm{~m}$ & & & $\mathrm{~m}$ & \\
\hline NFV I0\% & & & & & & & & & $\mathrm{m}$ & \\
\hline SQV I8\% & & & & & & $\mathrm{m}$ & & & $\mathrm{m}$ & \\
\hline TPV 29\% & & & $M$ & $M$ & & $\mathrm{~m}$ & $M$ & & $M$ & \\
\hline
\end{tabular}

Notes: Major darunavir mutations are in bold. Percentages are the number of shared mutations divided by the total number of resistance mutations for each drug. Abbreviations: M, major mutation; m, minor mutation; ATV, atazanavir; f-APV, fosamprenavir; IDV, indinavir; LPV, lopinavir; NFV, nelfinavir; SQV, saquinavir; TPV, tipranavir.

POWER cohort, these data strongly reinforce that a large number of PI mutations accumulate prior to the emergence of darunavir RAMs.

In addition to an association with virologic efficacy of darunavir therapy, the baseline mutation profile has been shown to be an important predictor of the mutational pattern that emerges with treatment-associated failure of the drug. Genotypes were obtained at baseline and at the time of failure in a cohort of 25 treatment experienced patients, all of whom failed to achieve or maintain virologic suppression while receiving darunavir for at least 3 months. ${ }^{33}$ Those with $\leq 1$ baseline darunavir RAM selected $\leq 1$ additional RAM at the time of failure, suggesting sub-optimal adherence was the likely cause. Those with $\geq 4$ baseline RAMs also selected $\leq 1$ additional RAM after failure, likely because the dominant viral isolate was already largely resistant to darunavir at baseline. In contrast, two-thirds of the patients with 2 to 3 baseline RAMs selected 2 to 5 additional RAMs after failure. Furthermore, among those with viral replication for $>24$ weeks on darunavir, additional RAMs were selected in $93 \%$, vs only $40 \%$ of those who stopped darunavir earlier.

In the much larger POWER cohort, at 24 weeks, overall there were $146(31 \%)$ of 458 patients who either rebounded or never achieved virologic suppression. ${ }^{31}$ In these, the most common observed mutation was V32I in 35\%. This mutation is one of the major mutations associated with failure in the Stanford resistance database, although IAS does not list it as a major mutation.

Prior failure with tipranavir does not seem to substantially increase the risk of acquiring darunavir RAMs, consistent with the preservation of tipranavir $\mathrm{IC}_{50}$ discussed in the previous section. In a small cohort of 47 patients, the Stanfordbased mutation score for darunavir did not significantly increase (worsen) after failure with tipranavir, compared with the score prior to starting tipranavir. ${ }^{34}$ The authors hypothesize that the preservation of darunavir activity after failure with tipranavir may be explained by an overlap in primary RAMs between darunavir and tipranavir of only four mutations: $33 \mathrm{~F}, 47 \mathrm{~V}, 54 \mathrm{M}$ and $84 \mathrm{~V}$. Conversely, viral isolates that are resistant to darunavir can be resistant in vitro to all other PIs except tipranavir. ${ }^{12}$ In clinical studies, patients who fail darunavir are more likely to preserve the activity of tipranavir than any other PI. ${ }^{33,35}$

In summary, 11 darunavir RAMs have been identified which contribute to therapeutic failure, especially when $\geq 3$ are present at baseline, and which emerge with failure of darunavir, especially if failing therapy is prolonged more than 6 months. A high number of PI RAMs must generally accumulate prior to selection of darunavir RAMs, suggesting a high genetic barrier that delays emergence of darunavir resistance. Failure with darunavir appears to preserve activity to tipranavir, if present at baseline. The converse is also true, that failure with tipranavir appears to preserve the activity of darunavir.

\section{Phenotypic susceptibility and outcomes}

According to the vircoTYPE HIV- $1^{\circledR}$ virtual phenotypic database (Virco, Inc.), there is a $20 \%$ loss of clinical activity when the in vitro $\mathrm{IC}_{50}$ of the patient's dominant viral strain is increased by 10-fold relative to wild type, and an $80 \%$ loss of activity when the $\mathrm{IC}_{50}$ is increased by 106.9 -fold. ${ }^{36}$ For the Phenosense ${ }^{\circledR}$ assay (Monogram, Inc.), the lower cutoff is the same, but due to methodologic differences the higher cutoff that defines resistance is a 40-fold increase in the $\mathrm{IC}_{50}{ }^{37}$ considerably lower than the vircoTYPE cutoff; therefore, resistance results from these two tests are not fully interchangeable.

In combined analysis of all three POWER studies, baseline virtual phenotypic susceptibility was highly predictive of the percent of patients with a viral load $<50$ copies $/ \mathrm{mL}$ at week 48 . Relative to wild-type virus, a $<10$-fold change 
in protein-adjusted $\mathrm{IC}_{50}$ was associated with a $50 \%$ rate of suppression, compared with $25 \%$ in the intermediate range (10- to 40 -fold), and $13 \%$ in the resistant range ( $>40$-fold). ${ }^{31}$ In the PREDZISTA study of 65 PI-experienced patients receiving darunavir as a component of salvage therapy, baseline fold change was also associated with outcome, ranging from virologic response in $68 \%$ with a fold change $<10$, to only $20 \%$ with a fold change $>40 .{ }^{32}$ Baseline resistance to darunavir was extremely low in both the ARTEMIS ${ }^{15}$ (treatment-naïve) and TITAN ${ }^{24}$ (moderately treatmentexperienced) studies, precluding any conclusions about relationship to the odds of virologic suppression.

Failure with darunavir appears to preserve the phenotypic sensitivity of tipranavir, the other nonpeptidic PI, if active at baseline. In the POWER cohort, those who failed darunavir therapy predictably had a 24-week median darunavir $\mathrm{IC}_{50} 91.1$ fold higher than wild type $\mathrm{IC}_{50}$, compared to a baseline fold change of only $12.6 .{ }^{31}$ Despite this increase in darunavir $\mathrm{IC}_{50}$, the median fold change in tipranavir $\mathrm{IC}_{50}$ was 2.6 at 24 weeks compared to 3.1 at baseline. Over $80 \%$ of isolates susceptible to tipranavir at baseline were still susceptible to tipranavir after failure with darunavir.

In summary, in large numbers of treatment-experienced patients, baseline phenotypic susceptibility was an important predictor of virologic suppression after starting darunavirbased combination antiretroviral therapy. Failure with darunavir does not appear to increase the tipranavir $\mathrm{IC}_{50}$, suggesting that the drugs have different mutational pathways to resistance. This will be discussed more in the next section.

\section{Concentrations, inhibitory quotients and outcomes}

In the POWER 1 and 2 cohorts, there was a statistically significant, but weak relationship between darunavir plasma AUC $(P=0.026)$ or trough concentration $(P=0.010)$ and $>1 \log _{10}$ reduction in viral load at week 24 compared with baseline. ${ }^{38}$ Baseline fold-change in darunavir $\mathrm{IC}_{50}$ and vIQ were each more strongly associated with the same outcome ( $P<0.001$ for both). Among those patients with a vIQ in the highest quartile $(>1.4), 84 \%$ had a viral load drop of more than $1 \log _{10}$ at week 24 , compared to only $32 \%$ of patients with a pIQ in the lowest quartile $(<0.1)$.

A smaller study in 37 PI-experienced adults also found an association between baseline vIQ and response, identified by viral suppression $<50$ copies/mL after 48 weeks of darunavir plus optimized background therapy. ${ }^{39}$ By Receiver-Operator Curve (ROC) analysis, the vIQ which best discriminated responders from nonresponders was 1.5. Among responders, $70.8 \%$ had a vIQ $\geq 1.5$, vs only $29.2 \%$ in nonresponders $(P=0.028)$. The median decrease in viral load from baseline in those with a vIQ $>1.5$ was $2.5 \log _{10}$ copies/mL, compared with only $0.27 \log _{10}$ copies $/ \mathrm{mL}$ for those with a vIQ $<1.5(P=0.004)$. In contrast to the POWER cohort, darunavir trough concentration $(\mathrm{P}=0.377)$, baseline PI RAMs $(P=0.918)$, baseline darunavir RAMs $(P=0.918)$, and baseline fold-change in darunavir $\mathrm{IC}_{50}$ $(P=0.651)$ were not significantly different in responders vs nonresponders.

The above study also examined the relationship between gIQ and virologic outcome. By ROC analysis, the gIQ which best discriminated responders from nonresponders was 2.4, but the percent of responders higher than this threshold was not significantly different from the percent of nonresponders (71.4\% vs $43.8 \%, P=0.105)$. The median decrease in viral load from baseline in those with a gIQ $>2.4$ was $2.5 \log _{10}$ copies/mL, compared with $1.6 \log _{10}$ copies/mL for those with a gIQ $<2.4(P=0.139)$. However, in the PREDZISTA study, a baseline gIQ of $\geq 1.8$ was predictive of response (viral load $<200$ copies $/ \mathrm{mL}$ ) after 12 weeks of darunavirbased therapy, with $55 \%$ of those with gIQ $<1.8$ failing to respond, vs none with gIQ $\geq 1.8(P<0.001) .{ }^{32}$

In summary, the antiviral efficacy of darunavir in patients is largely driven by susceptibility of the patient's dominant viral strain, whether measured by phenotype or genotype. However, incorporation of darunavir plasma concentrations in the form of an IQ contributes some additional information to prediction of virologic response. A possible vIQ target is 1.5 , while a candidate gIQ is 1.8 . These targets may be helpful in individual patients, but it is premature to recommend determination of the IQ as part of routine care.

\section{Safety and tolerability}

Major adverse effects in the DELPHI, POWER, ARTEMIS and TITAN trials are summarized in Table 5 and detailed here. In the DELPHI cohort, as might be expected in chronically ill children, average baseline height and weight were both 1.4 standard deviations below the mean of agematched healthy children. At week 48, mean z-score had increased by $0.1(P=0.136)$ for height and $0.2(P=0.003)$ for weight, indicating that the children were growing and gaining weight faster than age-matched peers. There were only two clinical adverse effects greater than grade 1 and judged to be treatment related: diarrhea and rash. Neither were treatment limiting. Laboratory abnormalities greater than grade 1 included a decreased absolute neutrophil count 
$(13 \%)$, increased pancreatic amylase $(11 \%)$, increased alanine aminotransferase (ALT, 6\%) and aspartate aminotransferase (AST, 5\%), and lipase (4\%). Again, none resulted in cessation of darunavir. Darunavir significantly reduced fasting triglyceride levels to within the normal range for adults. In contrast, total cholesterol, LDL and HDL all increased significantly, but remained below normal adult values. Approximately half of the children were receiving lopinavir/ritonavir at the time of study entry.

In the POWER 1 and 2 studies,,${ }^{19}$ the rates of adverse events higher than control were nausea (darunavir 18\%/ control $13 \%)$, nasopharyngitis (14\%/11\%), upper respiratory infection $(12 \% / 7 \%)$ and herpes simplex $(12 \% / 2 \%)$. The most common treatment-emergent grade 3 and 4 laboratory abnormalities in the darunavir group higher than control were increased triglycerides $(15 \% / 7 \%)$, increased pancreatic amylase $(6 \% / 5 \%)$, increased total cholesterol $(7 \% / 2 \%)$, and increased pancreatic lipase $(5 \% / 1 \%)$. No cases of clinical pancreatitis were observed in patients with lipase abnormalities.

In ARTEMIS, darunavir was also associated with increases in triglycerides (3\%), pancreatic amylase $(7 \%)$, and total cholesterol (13\%), but the lipid abnormalities were significantly higher in the lopinavir arm (11\% and 23\% for triglycerides and cholesterol) and similar for amylase $(5 \%) .{ }^{15}$ In TITAN, no adverse events $>$ Grade 1 that were judged to be related to study drug were more common in the darunavir arm. ${ }^{24}$ Laboratory abnormalities $>$ Grade 1 and at least possibly related to study drug which were more common in the darunavir arm included total cholesterol (32\%/29\%), low-density lipoprotein $(19 \% / 17 \%)$, pancreatic amylase $(11 \% / 9 \%)$, and pancreatic lipase $(5 \% / 4 \%)$.

The package insert contains additional safety information from the combined analysis of more than 3000 patients exposed to darunavir, and these are summarized in Table 9. ${ }^{12}$ Adverse reactions noted in all Phase II tests with $>$ Grade 1 intensity include abdominal pain, acute hepatitis, acute pancreatitis, anorexia, asthenia, diabetes mellitus, diarrhea, fatigue, headache, hepatic enzyme increased, hypercholesterolemia, hyperglycemia, hypertriglyceridemia, immune reconstitution syndrome, low density lipoprotein increased, nausea, pancreatic enzyme increased, rash, Stevens-Johnson Syndrome and vomiting.

In prelicensure testing, $0.5 \%$ of patients developed hepatitis, and additional postlicensure reports of hepatitis have accrued. Most patients had underlying or concomitant processes, such as co-infection with hepatitis B or C, which predisposed them to hepatitis. Nonetheless, baseline and routine monitoring of $\mathrm{AST} / \mathrm{ALT}$ is recommended, with increased frequency in those who are at risk prior to starting darunavir. Rashes were noted in $10 \%$, and were typically mild to moderate, occurred during the first month of therapy, and resolved spontaneously without the need for treatment discontinuation. Severe rash, accompanying a systemic hypersensitivity reaction with fever and elevated hepatic transaminases, occurred in $0.4 \%$ of patients, and StevensJohnson was reported in $0.1 \%$. Darunavir does contain a sulfa moiety, and thus should be used with caution in patients who have a sulfa allergy, although in clinical trials, the incidence of rash/hypersensitivity was the same regardless of the history of sulfa allergy. There have been reports of increased hemophilia A- or B -associated bleeding, in some cases requiring additional Factor VIII. Half of the cases did not result in discontinuation of the drug, and a causal relationship has not been established. Adverse effects common to all PIs, such as hyperglycemia, onset or worsening of diabetes mellitus, fat redistribution and immune reconstitution syndrome have all been reported for darunavir.

Finally, there is a specific warning in the package insert regarding use in young children. ${ }^{12}$ Due to observed toxicity and mortality in juvenile rats dosed with darunavir from $20 \mathrm{mg} / \mathrm{kg}$ to $1000 \mathrm{mg} / \mathrm{kg}$ up to days 23 to 26 of age, use of darunavir in children under 6 years of age is currently not recommended, although as mentioned previously, application for licensure in patients as young as 3 years of age is currently underway in Europe.

In summary, darunavir has a safety profile in children older than 6 years of age that is comparable to that observed in more than 3000 adults, with the main adverse effects related to gastrointestinal symptoms, lipid abnormalities, pancreatic enzyme elevations, and probable immune reconstitution phenomena. Overall, rates of these adverse events are similar to or better than comparator regimens, and no "black box warnings" have been identified by the FDA.

\section{Options for salvage therapy in children and adolescents}

The most recent US Department of Health and Human Services guidelines for antiretroviral therapy in children and adolescents contain a newly updated section on recommended choices for the next antiretroviral regimen for treatment failure with evidence of drug resistance. ${ }^{3}$ As for adults, the goal is $<50$ viral copies $/ \mathrm{mL}$ plasma, recognizing that this is not always possible. The strategy to select the salvage regimen is methodical, but becomes increasingly difficult as resistance accumulates, particularly in children who have fewer licensed therapeutic options than adults. 
Table 9 Rates of darunavir adverse events and laboratory abnormalities observed in treatment-experienced adults, Phase III clinical trial (adapted from US Package Insert) ${ }^{12}$

\begin{tabular}{|c|c|c|c|}
\hline & & $\begin{array}{l}\text { Darunavir/ritonavir } \\
600 / 100 \mathrm{mg} \text { twice daily + } \\
\text { optimized background } \\
\mathrm{N}=298\end{array}$ & $\begin{array}{l}\text { Lopinavir/ritonavir } \\
400 / 100 \mathrm{mg} \text { twice daily }+ \\
\text { optimized background } \\
\mathrm{N}=297\end{array}$ \\
\hline \multicolumn{4}{|l|}{ Gastrointestinal disorders } \\
\hline Abdominal distension & & $2 \%$ & $<1 \%$ \\
\hline Abdominal pain & & $5 \%$ & $2 \%$ \\
\hline Diarrhea & & $12 \%$ & $18 \%$ \\
\hline Dyspepsia & & $2 \%$ & $<1 \%$ \\
\hline Flatulence & & $<1 \%$ & $1 \%$ \\
\hline Nausea & & $7 \%$ & $6 \%$ \\
\hline Vomiting & & $4 \%$ & $3 \%$ \\
\hline \multicolumn{4}{|c|}{ General disorders and administration site conditions } \\
\hline Asthenia & & $3 \%$ & $1 \%$ \\
\hline Fatigue & & $1 \%$ & $1 \%$ \\
\hline \multicolumn{4}{|c|}{ Metabolism and nutrition disorders } \\
\hline Anorexia & & $1 \%$ & $2 \%$ \\
\hline Diabetes mellitus & & $<1 \%$ & $0 \%$ \\
\hline \multicolumn{4}{|c|}{ Musculoskeletal and connective tissue disorders } \\
\hline Myalgia & & $1 \%$ & $<1 \%$ \\
\hline \multicolumn{4}{|l|}{ Nervous system disorders } \\
\hline Headache & & $2 \%$ & $3 \%$ \\
\hline \multicolumn{4}{|l|}{ Psychiatric disorders } \\
\hline Abnormal dreams & & $<1 \%$ & $0 \%$ \\
\hline \multicolumn{4}{|c|}{ Skin and subcutaneous tissue disorders } \\
\hline Pruritus & & $<1 \%$ & $1 \%$ \\
\hline Rash & & $6 \%$ & $3 \%$ \\
\hline \multicolumn{4}{|l|}{ Laboratory parameters } \\
\hline \multicolumn{4}{|c|}{ Alanine aminotransferase } \\
\hline Grade 2 & $>2.5$ to $\leq 5.0 \times$ ULN & $6 \%$ & $5 \%$ \\
\hline Grade 3 & $>5.0$ to $\leq 10.0 \times$ ULN & $2 \%$ & $2 \%$ \\
\hline Grade 4 & $>10.0 \times$ ULN & $1 \%$ & $2 \%$ \\
\hline \multicolumn{4}{|c|}{ Aspartate aminotransferase } \\
\hline Grade 2 & $>2.5$ to $\leq 5.0 \times$ ULN & $4 \%$ & $6 \%$ \\
\hline Grade 3 & $>5.0$ to $\leq 10.0 \times$ ULN & $2 \%$ & $2 \%$ \\
\hline Grade 4 & $>10.0 \times$ ULN & $<1 \%$ & $2 \%$ \\
\hline \multicolumn{4}{|l|}{ Alkaline phosphatase } \\
\hline Grade 2 & $>2.5$ to $\leq 5.0 \times$ ULN & $<1 \%$ & $0 \%$ \\
\hline Grade 3 & $>5.0$ to $\leq 10.0 \times$ ULN & $<1 \%$ & $<1 \%$ \\
\hline Grade 4 & $>10.0 \times U L N$ & $0 \%$ & $0 \%$ \\
\hline \multicolumn{4}{|l|}{ Hyperbilirubinemia } \\
\hline Grade 2 & $>1.5$ to $\leq 2.5 \times$ ULN & $0 \%$ & $1 \%$ \\
\hline Grade 3 & $>2.5$ to $\leq 5.0 \times$ ULN & $<1 \%$ & $0 \%$ \\
\hline Grade 4 & $>5.0 \times$ ULN & $<1 \%$ & $0 \%$ \\
\hline \multicolumn{4}{|l|}{ Triglycerides } \\
\hline \multirow[t]{2}{*}{ Grade 2} & $5.65-8.48 \mathrm{mmol} / \mathrm{L}$ & $11 \%$ & $11 \%$ \\
\hline & $500-750 \mathrm{mg} / \mathrm{dL}$ & & \\
\hline
\end{tabular}


Table 9 (Continued)

\begin{tabular}{|c|c|c|c|}
\hline & & $\begin{array}{l}\text { Darunavir/ritonavir } \\
600 / 100 \mathrm{mg} \text { twice daily }+ \\
\text { optimized background } \\
\mathrm{N}=298\end{array}$ & $\begin{array}{l}\text { Lopinavir/ritonavir } \\
400 / 100 \text { mg twice daily }+ \\
\text { optimized background } \\
N=297\end{array}$ \\
\hline Grade 3 & $\begin{array}{l}8.49-13.56 \mathrm{mmol} / \mathrm{L} \\
75 \mathrm{I}-1200 \mathrm{mg} / \mathrm{dL}\end{array}$ & $7 \%$ & $9 \%$ \\
\hline Grade 4 & $\begin{array}{l}>13.56 \mathrm{mmol} / \mathrm{L} \\
>1200 \mathrm{mg} / \mathrm{dL}\end{array}$ & $2 \%$ & $5 \%$ \\
\hline \multicolumn{4}{|c|}{ Total cholesterol } \\
\hline Grade 2 & $\begin{array}{l}6.20-7.77 \mathrm{mmol} / \mathrm{L} \\
240-300 \mathrm{mg} / \mathrm{dL}\end{array}$ & $24 \%$ & $19 \%$ \\
\hline Grade 3 & $\begin{array}{l}>7.77 \mathrm{mmol} / \mathrm{L} \\
>300 \mathrm{mg} / \mathrm{dL}\end{array}$ & $8 \%$ & $11 \%$ \\
\hline \multicolumn{4}{|c|}{ Low-density lipoprotein cholesterol } \\
\hline Grade 2 & $\begin{array}{l}4.13-4.90 \mathrm{mmol} / \mathrm{L} \\
160-190 \mathrm{mg} / \mathrm{dL}\end{array}$ & $13 \%$ & $11 \%$ \\
\hline Grade 3 & $\begin{array}{l}\geq 4.91 \mathrm{mmol} / \mathrm{L} \\
\geq 191 \mathrm{mg} / \mathrm{dL}\end{array}$ & $7 \%$ & $8 \%$ \\
\hline \multicolumn{4}{|c|}{ Elevated glucose levels } \\
\hline Grade 2 & $\begin{array}{l}6.95-13.88 \mathrm{mmol} / \mathrm{L} \\
126-250 \mathrm{mg} / \mathrm{dL}\end{array}$ & $8 \%$ & $9 \%$ \\
\hline Grade 3 & $\begin{array}{l}13.89-27.75 \mathrm{mmol} / \mathrm{L} \\
25 \mathrm{I}-500 \mathrm{mg} / \mathrm{dL}\end{array}$ & $<1 \%$ & $<1 \%$ \\
\hline Grade 4 & $\begin{array}{l}>27.75 \mathrm{mmol} / \mathrm{L} \\
>500 \mathrm{mg} / \mathrm{dL}\end{array}$ & $<1 \%$ & $0 \%$ \\
\hline \multicolumn{4}{|c|}{ Pancreatic lipase } \\
\hline Grade 2 & $>1.5$ to $\leq 3.0 \times$ ULN & $2 \%$ & $4 \%$ \\
\hline Grade 3 & $>3.0$ to $\leq 5.0 \times$ ULN & $2 \%$ & $<1 \%$ \\
\hline Grade 4 & $>5.0 \times$ ULN & $<1 \%$ & $0 \%$ \\
\hline \multicolumn{4}{|c|}{ Pancreatic amylase } \\
\hline Grade 2 & $>1.5$ to $\leq 2.0 \times$ ULN & $6 \%$ & $6 \%$ \\
\hline Grade 3 & $>2.0$ to $\leq 5.0 \times$ ULN & $6 \%$ & $3 \%$ \\
\hline Grade 4 & $>5.0 \times$ ULN & $0 \%$ & $0 \%$ \\
\hline
\end{tabular}

Abbreviations: ULN, upper limit of normal.

Optimally, all regimens should contain at least two, but preferably three fully active drugs.

For children failing an NNRTI-based regimen, the next regimen should be based on a PI. This is because primary resistance to either efavirenz or nevirapine (the first generation NNRTIs) confers resistance to the other drug, via the K103N mutation. Currently, the second-generation NNRTI, etravirine, which is active against many isolates that are resistant to first-generation NNRTIs, is not approved under the age of 18. This is likely to change in the near future, as Phase 1 testing in children is complete ${ }^{40}$ and a proposed dose of $5.2 \mathrm{mg} / \mathrm{kg}$ twice daily will be tested in the currently enrolling Phase 2 PIANO (Pediatric trial with Intelence as an Active NNRTI Option) study of treatment-experienced children and adolescents over the age of 6 years. ${ }^{41}$
Conversely, failure on a PI-based regimen leaves several options for subsequent therapy depending on prior exposure and tolerability concerns. These options are NNRTI-based therapy, alternative PI-based therapy with ritonavir boosting, or NNRTI + boosted PI-based therapy. Finally, in the setting of failure with prior exposure to both PIs and NNRTIs, the guidelines recommend either a newer ritonavir-boosted PI (darunavir or tipranavir), dual-boosted PI combinations (lopinavir/ritonavir plus either atazanavir or saquinavir), and/or the use of efuvirtide, etravirine, raltegravir, or maraviroc.

In these "deep salvage" scenarios, pediatric providers can encounter the need for drugs with no FDA-licensure in the pediatric population (Table 1), or even no published data. In general, newer therapeutic classes or newer drugs 
in older classes will be required to treat these patients. Since maraviroc and raltegravir are not approved for use under the age of 16 years, and dosing information is unavailable for either drug in children, treatment with these agents is currently best initiated in the context of a clinical trial. Etravirine is not yet licensed for those less than 16 years of age, and although there is a candidate pediatric dose, safety and efficacy of this dose have not yet been established.

In the guidelines, ${ }^{3}$ lopinavir/ritonavir is currently listed as a preferred agent for initial therapy in children, and therefore would be the preferred agent for salvage therapy after failure with NNRTIs or perhaps another PI such as nelfinavir. It has been shown to be safe, effective, and durable in children and adolescents in this setting. ${ }^{42,43}$ Fos-amprenavir/ritonavir has been shown to be noninferior to lopinavir/ritonavir in the treatment of treatment-naïve adults, ${ }^{44}$ and to have good long-term virologic suppression in a noncomparative study of treatment-experienced adults, ${ }^{45}$ but it has not been studied for salvage therapy in children.

Tipranavir has been studied in treatment-experienced children and is the drug most likely to be considered against darunavir for deep salvage therapy due to the largely nonoverlapping resistance profiles (see section on Resistance Mutations above). Table 10 summarizes the comparison between darunavir and tipranavir, which is detailed here. The Pediatric AIDS Clinical Trials Group (PACTG), now the
International Maternal Pediatric Adolescent AIDS Clinical Trials (IMPAACT) group co-sponsored the P1051 study with the manufacturer to evaluate the safety, tolerability and efficacy of tipranavir in treatment-naïve and -experienced children aged 2 to 18 years, although $97 \%$ of the enrollees were treatment-experienced. ${ }^{46}$ Baseline characteristics of the P1051 study population $(n=115)$ were similar to the DELPHI participants, with a median of 7 antiretroviral drugs used previously and 13 PI mutations per patient. There were two doses studied, the higher of which was tipranavir $375 \mathrm{mg} / \mathrm{m}^{2}$ plus ritonavir $150 \mathrm{mg} / \mathrm{m}^{2}$ twice daily $(\mathrm{n}=57)$, and was the dose that was eventually licensed by the FDA. In that group, $35.1 \%$ had a viral load of $<50$ copies $/ \mathrm{mL}$ at 48 weeks and a median change in CD4+ cell count of +59 cells $/ \mathrm{mm}^{3}$. A high percentage of children in the highdose cohort experienced adverse effects, the most common being vomiting (42\%), cough (30\%), diarrhea (26\%), pyrexia $(21 \%)$, nausea $(18 \%)$, nasopharyngitis $(12 \%)$ and headache (11\%). Overall, $60 \%$ of the high-dose participants had an adverse effect judged to be related to the study drug in some way, and $7 \%$ stopped the drug due to the adverse effect. Grade 3 elevations in ALT occurred in 6\%; bleeding occurred in $14 \%$ of those receiving capsules; there were no reported Grade 3 or higher elevations in triglycerides.

The overall proportion of patients with a serious adverse event was $25 \%$, and this was marginally significantly higher

Table 10 Comparison between darunavir and tipranavir

\begin{tabular}{|c|c|c|}
\hline & Darunavir & Tipranavir \\
\hline \multicolumn{3}{|l|}{ FDA licensure } \\
\hline Age & $\geq 6$ years of age & $\geq 2$ years of age \\
\hline Pediatric & Treatment-experienced & Treatment-experienced \\
\hline \multicolumn{3}{|l|}{ Indication } \\
\hline Available formulations & $75,300,400$ and $600 \mathrm{mg}$ film-coated tablets & $250 \mathrm{mg}$ capsules $100 \mathrm{mg} / \mathrm{mL}$ solution \\
\hline Dosing frequency & Twice daily & Twice daily \\
\hline Daily pill burden & 4 & 8 \\
\hline (maximum dose) & & \\
\hline \multirow[t]{2}{*}{ Drug interactions } & +++ (largely due to ritonavir) & ++++ (due to tipranavir and ritonavir) \\
\hline & DELPHI, $\mathrm{n}=80^{10}$ & $\mathrm{PI05I}, \mathrm{n}=115^{46}$ \\
\hline \multicolumn{3}{|l|}{ Baseline } \\
\hline Prior ARV exposure (median number) & 9 & 7 \\
\hline PI resistance mutation (median number) & $\mathrm{II}$ & 13 \\
\hline \multicolumn{3}{|l|}{ 48-week efficacy } \\
\hline $\mathrm{VL}<50$ copies $/ \mathrm{mL}$ & $48 \%$ & $35 \%$ \\
\hline$\Delta \mathrm{CD} 4+$ cells $/ \mathrm{mm}^{3}$ & +147 & +59 \\
\hline \multicolumn{3}{|l|}{ Rate of adverse effects } \\
\hline Any & $94 \%$ & $94 \%$ \\
\hline Serious & $14 \%$ & $25 \%$ \\
\hline
\end{tabular}

Abbreviations: ARV, antiretroviral; PI, protease inhibitors; VL, viral load. 
than in the DELPHI study, ${ }^{10}$ where the rate was $14 \%$ ( $P=0.05$, Chi square). The proportions of patients in the DELPHI and P1051 studies with any adverse event were the same: $94 \%$ vs $94 \%$.

In summary, then, how does tipranavir compare with darunavir? Both are dosed with ritonavir, and both are administered twice daily. Tipranavir has tablet and liquid formulations, while darunavir is only supplied as tablets. Although the dosing frequency of each is the same, the pill burden for the full adolescent dose is lower for darunavir/ ritonavir, with 2 tablets twice daily, vs 4 tablets twice daily for tipranavir/ritonavir. Darunavir is licensed for children as young as 6 years of age, while tipranavir is licensed for those as young as 2 years of age. Efficacy rates are similar, or slightly higher for darunavir. The rate of serious adverse effects in the DELPHI study for darunavir was less than in the P1051 study for tipranavir, but the overall rate of adverse events, without regard to cause, was the same for the two drugs. Drug interaction potential for both drugs is high, but somewhat higher for tipranavir due to its ability to broadly induce and inhibit the activity of numerous drug metabolizing enzymes. ${ }^{47}$ In our clinic, which provides care to over $100 \mathrm{HIV}$-infected children and adolescents, we prefer to use darunavir before tipranavir due to darunavir's lower overall pill burden, lower ritonavir dose, and more predictable drug interactions; however, available evidence does not distinguish a preferred order of sequencing darunavir and tipranavir based on efficacy.

\section{Conclusions/recommendations}

Darunavir offers a safe and potent new choice of therapy to clinicians who care for HIV-infected children and adolescents. Because it has not been studied in treatment-naïve children, and there are numerous other first-line agents, and because laboratory evidence indicates that isolates which become resistant to darunavir can be resistant to all other PIs except tipranavir, use of darunavir should be restricted to salvage therapy. In this role it has activity against isolates which are highly resistant to other PIs. There are consistent genotypic and phenotypic predictors of virologic response to darunavir therapy to aid clinicians in evaluating the likelihood of success prior to initiating therapy. Additionally, there are less extensive data supporting phenotypic or genotypic inhibitory quotients which could be used to adjust therapy in selected patients if necessary.

Currently, the most likely pediatric population for whom darunavir would be useful is those who were infected with $\mathrm{HIV}$ at or near the time of birth and who have developed substantial antiretroviral drug resistance as they have matured. Transmission of multi-drug resistant HIV from mother to child is thus far very rare, and limited to case reports. ${ }^{17,48,49}$ Adolescents who are infected through sexual contact or intravenous drug abuse generally will mature into adulthood before they have sufficient antiretroviral exposure to accumulate large numbers of resistance mutations which would warrant darunavir therapy.

Therapy for perinatally infected adolescents with multi-drug resistant virus remains extremely challenging due to adherence and other psychosocial issues. ${ }^{3,50}$ Nonetheless, for selected children and adolescents who have likely already failed NNRTI-based therapy, and regimens based on atazanavir and lopinavir, darunavir with ritonavir offers a well tolerated, potent combination, with a relatively low pill burden, and which can have a substantial chance of virologic and immunologic benefit even with few additional active agents.

\section{Disclosure}

The authors declare no conflicts of interest.

\section{References}

1. Joint United Nations Programme on HIV/AIDS. 2008 Report on the global AIDS epidemic. http://www.unaids.org/en/KnowledgeCentre/ HIVData/GlobalReport/2008/2008_Global_report.asp. Accessed April 29, 2009.

2. Malhotra A, Gaur S, Whitley-Williams P, Loomis C, Petrova A. Protease inhibitor associated mutations compromise the efficacy of therapy in human immunodeficiency virus-1 (HIV-1) infected pediatric patients: a cross-sectional study. AIDS Res Ther. 2007;4:15.

3. Working Group on Antiretroviral Therapy and Medical Management of HIV-Infected Children. Guidelines for the Use of Antiretroviral Agents in Pediatric HIV Infection. February 23, 2009. http:// aidsinfo.nih.gov/ContentFiles/PediatricGuidelines.pdf. Accessed April 2, 2009.

4. Dierynck I, De Wit M, Gustin E, et al. Binding kinetics of darunavir to human immunodeficiency virus type 1 protease explain the potent antiviral activity and high genetic barrier. $J$ Virol. 2007;81(24): 13845-13851.

5. De Meyer S, Azijn H, Surleraux D, et al. TMC114, a novel human immunodeficiency virus type 1 protease inhibitor active against protease inhibitor-resistant viruses, including a broad range of clinical isolates. Antimicrob Agents Chemother. 2005;49(6):2314-2321.

6. Koh Y, Nakata H, Maeda K, et al. Novel bis-tetrahydrofuranylurethanecontaining nonpeptidic protease inhibitor (PI) UIC-94017 (TMC114) with potent activity against multi-PI-resistant human immunodeficiency virus in vitro. Antimicrob Agents Chemother. 2003;47(10): 3123-3129.

7. 21CFR201.57(a)(c)(9)(iv)(A). http://www.accessdata.fda.gov/ scripts/cdrh/cfdocs/cfcfr/CFRSearch.cfm?fr=201.57. Accessed April 6, 2009.

8. Bologna R, Rugina S, Cahn P, et al. Safety and Efficacy of Darunavir Co-administered with Low-dose Ritonavir in Treatment-experienced Children and Adolescents at Week 24. In: Program and Abstracts, 15th Conference on Retroviruses and Opportunistic Infections; 2008: abstract 78LB. http://www.retroconference.org/2008/Abstracts/33380. htm. Accessed March 16, 2009. 
9. Sekar V, Van de Casteele T, Van Beelan B, et al. Dose selection and pharmacokinetics-pharmacodynamics (PK-PD) of darunavir coadministered with low-dose ritonavir (DRV/r) in the DELPHI (TMC114-C212) trial in treatment-experienced, HIV-1-infected children and adolescents. In: Program and Abstracts, 17th International AIDS Conference; 2008: abstract TUPE0078. http://www.iasociety.org/Default.aspx?pageId=1 1\&abstractId=200713841. Accessed March 23, 2009.

10. Blanche S, Bologna R, Cahn P, et al. 48-wk Safety and efficacy of darunavir/ritonavir (DRV/r) in treatment-experienced children and adolescents in DELPHI. In: Program and Abstracts, ICAAC/IDSA 2008; abstract H-894.

11. Sekar V, Kestens D, Spinosa-Guzman S, et al. The effect of different meal types on the pharmacokinetics of darunavir (TMC114)/ritonavir in HIV-negative healthy volunteers. J Clin Pharmacol. 2007;47: 479-484.

12. Prezista [US Package Insert]. http://www.prezista.com. Accessed March 23, 2009.

13. Vermeir M, Lachau-Durand S, Mannens G, et al. Absorption, metabolism, and excretion of darunavir, a new protease inhibitor, administered alone and with low-dose ritonavir in healthy subjects. Drug Metab Dispos. 2009;37(4):809-820.

14. Katlama C, Esposito R, Gatell JM, et al. Efficacy and safety of TMC114/ ritonavir in treatment-experienced HIV patients: 24-week results of POWER 1. AIDS. 2007;21:395-402.

15. Ortiz R, Dejesus E, Khanlou H, et al. Efficacy and safety of once-daily darunavir/ritonavir versus lopinavir/ritonavir in treatment-naive HIV-1infected patients at week 48. AIDS. 2008;22(12):1389-1397.

16. Foisy MM, Yakiwchuk EM, Hughes CA. Induction effects of ritonavir: implications for drug interactions. Ann Pharmacother. 2008; 42(7):1048-1059.

17. Viganò A, Meroni L, Marchetti G, et al. Successful rescue therapy with a darunavir/ritonavir and etravirine antiretroviral regimen in a child with vertically acquired multidrug-resistant HIV-1. Antivir Ther. 2008;13(6):839-843.

18. Guidance for Industry-Antiretroviral Drugs Using Plasma HIV RNA Measurements - Clinical Considerations for Accelerated and Traditional Approval. http://www.fda.gov/cder/guidance/3647fnl.htm. Accessed April 1, 2009.

19. Clotet B, Bellos N, Molina JM, et al. Efficacy and safety of darunavirritonavir at week 48 in treatment-experienced patients with HIV-1 infection in POWER 1 and 2: a pooled subgroup analysis of data from two randomised trials. Lancet. 2007;369:1169-1178.

20. Molina J, Cohen C, Katlama C, et al. Safety and efficacy of darunavir (TMC114) with low-dose ritonavir in treatment-experienced patients: 24-week results of POWER 3. J Acquir Immune Defic Syndr. 2007; 46(1):24-31.

21. Poveda E, de Mendoza C, Martin-Carbonero L, et al. Prevalence of darunavir resistance mutations in $\mathrm{HIV}$-1-infected patients failing other protease inhibitors. J Antimicrob Chemother. 2007;60:885-888.

22. Picchio G, Vangeneugden T, Van Baelen B, et al. Prior utilization or resistance to amprenavir at screening has minimal effect on the 48-Week response to darunavir/ $\mathrm{r}$ in the POWER 1, 2, and 3 studies. In: Program and Abstracts, 14th Conference on Retroviruses and Opportunistic Infections; 2007:abstract 609 .

23. Picchio G, De Meyer S, de Bethune MP. Response to "key amprenavir resistance mutations counteract dramatic efficacy of darunavir in highly experienced patients". AIDS. 2008;22:165-167.

24. Madruga JV, Berger D, McMurchie M, et al. Efficacy and safety of darunavir-ritonavir compared with that of lopinavir-ritonavir at 48 weeks in treatment-experienced, HIV-infected patients in TITAN: a randomised controlled phase III trial. Lancet. 2007;370(9581): 49-58.

25. Chen TK, Aldrovandi GM. Review of HIV antiretroviral drug resistance. Pediatr Infect Dis J. 2008;27(8):749-752.

26. Vermeiren H, Van Craenenbroeck E, Alen P, et al. Prediction of HIV-1 drug susceptibility phenotype from the viral genotype using linear regression modeling. J Virol Methods. 2007;145(1):47-55.
27. Hoefnagel JGM, Koopmans PP, Burger DM, Schuurman R, Galama JMD. Role of the inhibitory quotient in HIV therapy. Antivir Ther. 2005;10(8):879-892.

28. De Meyer S, Dierynck I, Lathouwers E, et al. Phenotypic and genotypic determinants of resistance to daruanvir: analysis of data from treatmentexperienced patients in POWER 1,2,3 and DUET-1 and 2. Antivir Ther. 2008;13 Suppl 3:A33.

29. Johnson VA, Brun-Vezinet F, Clotet B, et al. Update of the drug resistance mutations in HIV-1. Top HIV Med. 2008;16(5):138-145.

30. Winters B, Vermeiren H, Van Craenenbroeck E, et al. Development of Virco ${ }^{\circledR}$ TYPE resistance analysis, including clinical cut-offs, for TMC114. In: Program and Abstracts, 15th International HIV Drug Resistance Workshop; 2006; abstract 160.

31. de Meyer S, Vangeneugden T, van Baelen B, et al. Resistance profile of darunavir: combined 24-week results from the POWER trials. AIDS Res Hum Retroviruses. 2008;24(3):379-388.

32. Pellegrin I, Wittkop L, Joubert LM, et al. Virological response to darunavir/ritonavir-based regimens in antiretroviral-experienced patients (PREDIZISTA study). Antivir Ther. 2008;13(2):271-279.

33. Delaugerre C, Pavie J, Palmer P, et al. Pattern and impact of emerging resistance mutations in treatment experienced patients failing darunavircontaining regimen. AIDS. 2008;22(14):1809-1813.

34. Spagnuolo V, Gianotti N, Seminari E, et al. Changes in darunavir/r resistance score after previous failure to tipranavir/r in HIV-1infected multidrug-resistant patients. J Acquir Immune Defic Syndr. 2009;50(2):192-195

35. Lambert-Niclot S, Flandre P, Canestri A, et al. Factors associated with the selection of mutations conferring resistance to protease inhibitors (PIs) in PI-experienced patients displaying treatment failure on darunavir. Antimicrob Agents Chemother. 2008;52:491-496.

36. vircoTYPE HIV-1 Clinical Cut-offs. http://www.vircolab.com. Accessed March 16, 2009.

37. PhenoSense HIV for reverse transcriptase and protease inhibitors assay. http://www.monogrambio.com. Accessed March 16, 2009

38. Sekar V, De Meyer S, Vangeneugden T, et al. Pharmacokinetic/ parmacodynamic analyses of TMC114 in the POWER 1 and POWER 2 trials in treatment-experienced HIV-infected patients. In: Program and Abstracts, 13th Conference on Retroviruses and Opportunistic Infections; 2003; abstract 639b.

39. Moltó J, Santos JR, Pérez-Alvarez N, et al. Darunavir inhibitory quotient predicts the 48-week virological response to darunavir-based salvage therapy in human immunodeficiency virus-infected protease inhibitor-experienced patients. Antimicrob Agents Chemother. 2008; 52(11):3928-3932.

40. Konigs C, Feiterna-Sperling C, Esposito S, et al. Pharmacokinetics and dose selection of etravirine in HIV-infected children between 6 and 17 years, inclusive. In: Program and Abstracts, 16th Conference on Retroviruses and Opportunistic Infections; 2009; abstract 879.

41. TMC125-TiDP35-C213: Safety and antiviral activity of etravirine (TMC125) in treatment-experienced, HIV infected children and adolescents. http://www.clinicaltrials.gov/ct2/show/NCT00665847? term=intelence\&rank=11. Accessed April 6, 2009.

42. Larrú B, Resino S, Bellón JM, et al. Long-term response to highly active antiretroviral therapy with lopinavir/ritonavir in pre-treated vertically HIV-infected children. J Antimicrob Chemother. 2008;61(1): 183-190.

43. Resino S, Bellón JM, Muñoz-Fernández MA. Antiretroviral activity and safety of lopinavir/ritonavir in protease inhibitor-experienced HIV-infected children with severe-moderate immunodeficiency. $J$ Antimicrob Chemother. 2006;57(3):579-582.

44. Eron J, Yeni P, Gathe J, et al. The KLEAN study of fosamprenavirritonavir versus lopinavir-ritonavir, each in combination with abacavirlamivudine, for initial treatment of HIV infection over 48 weeks: a randomised non-inferiority trial. Lancet. 2006;368(9534):476-482.

45. Quercia R, Garnier E, Ferré V, et al. Salvage therapy with ritonavirboosted amprenavir/fosamprenavir: virological and immunological response in two years follow-up. HIV Clin Trials. 6(2):73-80. 
46. Salazar JC, Cahn P, Yogev R, et al. Efficacy, safety and tolerability of tipranavir coadministered with ritonavir in HIV-1-infected children and adolescents. AIDS. 2008;22(14):1789-1798.

47. Aptivus Prescribing Information. http://www.aptivus.us/patient/index. jsp. Accessed April 7, 2009.

48. Cohan D, Feakins C, Wara D, et al. Perinatal transmission of multidrugresistant HIV-1 despite viral suppression on an enfuvirtide-based treatment regimen. AIDS. 2005;19(9):989-990.

49. Desai N, Mathur M. Selective transmission of multidrug resistant HIV to a newborn related to poor maternal adherence. Sex Transm Infect. 2003;79(5):419-421.

50. Panel on Antiretroviral Guidelines for Adult and Adolescents. Guidelines for the use of antiretroviral agents in HIV-1-infected adults and adolescents. Department of Health and Human Services. November 3, 2008. p 1-139. http://www.aidsinfo.nih.gov/ContentFiles/ AdultandAdolescentGL.pdf. Accessed January 21, 2009.

51. Darunavir: Summary of Product Characteristics. http://www.emea. europa.eu/. Accessed March 23, 2009

52. Sekar VJ, De Pauw M, Mariën K, et al. Pharmacokinetic interaction between TMC114/r and efavirenz in healthy volunteers. Antivir Ther (Lond). 2007;12(4):509-514.

53. Sekar VJ, Lefebvre E, Mariën K, et al. Pharmacokinetic interaction between darunavir and saquinavir in HIV-negative volunteers. Ther Drug Monit. 2007;29(6):795-801.
54. Sekar VJ, Lefebvre E, De Marez T, et al. Pharmacokinetics of darunavir (TMC114) and atazanavir during coadministration in HIV-negative, healthy volunteers. Drugs R D. 2007;8:241-248.

55. Sekar VJ, Lefebvre E, De Paepe E, et al. Pharmacokinetic interaction between darunavir boosted with ritonavir and omeprazole or ranitidine in human immunodeficiency virus-negative healthy volunteers. Antimicrob Agents Chemother. 2007;51(3):958-961.

56. Sekar VJ, Spinosa-Guzman S, De Paepe E, et al. Darunavir/ritonavir pharmacokinetics following coadministration with clarithromycin in healthy volunteers. J Clin Pharmacol. 2008;48(1):60-65.

57. Sekar VJ, Lefebvre E, De Pauw M, Vangeneugden T, Hoetelmans RM. Pharmacokinetics of darunavir/ritonavir and ketoconazole following co-administration in HIV-healthy volunteers. Br J Clin Pharmacol. 2008;66(2):215-221.

58. Sekar VJ, Lefebvre E, Guzman SS, et al. Pharmacokinetic interaction between ethinyl estradiol, norethindrone and darunavir with low-dose ritonavir in healthy women. Antivir Ther. 2008;13(4):563-569.

59. Sekar V, Lefebvre E, De Marez T, et al. Effect of repeated doses of darunavir plus low-dose ritonavir on the pharmacokinetics of sildenafil in healthy male subjects: phase I randomized, open-label, two-way crossover study. Clin Drug Investig. 2008;28(8):479-485.
Therapeutics and Clinical Risk Management

\section{Publish your work in this journal}

Therapeutics and Clinical Risk Management is an international, peerreviewed journal of clinical therapeutics and risk management, focusing on concise rapid reporting of clinical studies in all therapeutic areas, outcomes, safety, and programs for the effective, safe, and sustained use of medicines. This journal is indexed on PubMed Central, CAS,

\section{Dovepress}

EMBase, Scopus and the Elsevier Bibliographic databases. The manuscript management system is completely online and includes a very quick and fair peer-review system, which is all easy to use. Visit http://www.dovepress.com/testimonials.php to read real quotes from published authors.

Submit your manuscript here: http://www.dovepress.com/therapeutics-and-clinical-risk-management-journal 